\title{
Evaluation of the 1995 Predictions of the Run-Timing of Wild Migrant Yearling Chinook in the Snake River Basin using Program RealTime
}

\author{
Prepared by: \\ Richard L. Townsend \\ Peter Westhagen \\ Dean Yasuda \\ John R. Skalski \\ Kristen Ryding \\ Center for Quantitative Science \\ School of Fisheries \\ University of Washington \\ Seattle, Washington
}

Prepared for:

U.S. Department of Energy

Bonneville Power Administration

Environment, Fish and Wildlife

P.O. Box 3621

Portland, OR 97208-362 I

Project No. 9 I-05 I

Task Number DE-AT79-9 I BP 16570

Contract Number DE-BI79-87BP35885

September 1996 
This page intentionally left blank. 


\section{Table of Contents}

List of Figures

Page

List of Tables

Preface

Acknowledgements

Vii

Executive Summary

viii

Introduction

ix

Methods

Description of Data

Prediction Models

New Least-Squares (NLS) Algorithm

Least-squares (LS) Error

Release-Recapture (RR) Error

Age-of-Run (AR) Error

Calculation of the Total Error

Calculation of Comparison Scores

Results

$\begin{array}{ll}\text { Discussion } & 15\end{array}$

$\begin{array}{ll}\text { Literature Cited } & 16\end{array}$

Appendix A

redTime Performance Plots for the 1995 Outmigration Season

\section{Appendix B}

Comparison of historical recovery rates

\section{Appendix C}

Graphical Capabilities of the Realtime Program 


\section{List of Figures}

\section{Figure}

1 RealTimespill adjustment compared to a one-to-one conversion. 3

2 Day-to-day predictions and the daily comfidence intervals compared to the observed 9 run for 1995 season

31995 passage dates (10\%,50\%, $90 \%$ and range) at Lower Granite Dam for PIT-tagged 13 wild Snake River spring/summer chinook salmon molts for the 13 individual streams used in the composite and the composite run of program RealTime. based on the PITtagging of parr in 1994

Appendix A - RealTime Program Plots

Bear Valley Creek

BigCreek

Catherine Creek

ElkCreek

Grande Ronde River

Imnaha River

Lostine River

MarshCreek

Salmon River

Salmon River East Fork

Salmon River South Fork

Secesh River

Valley Creek

Composite Summary

Appendix C - Graphical Capabilities of the RealTime Program

RealTime base window

Individual streams

stream window

raw detections window

spill-adjusted detections window

cumulative detections window 
slope density window

results windcnv

daily predictions window

best prediction and forecast window

prediction slope density window

composite runs

composite window

daily predictions window (even-weighted composite run)

prediction and forecast window

prediction slope density window 


\section{List of Tables}

Table

Page

The thirteen individual rivers used in evaluating the predictive performance of the RealTime program

2 Summary for the thirteen streams used in the 1995 evaluation of the PIT-Porecaster program showing (1) wild chinook salom parr released in 1994. (2) dectected number of smolts at Lower Granite Dam in 1995, (3) number of years of historical data. (4) average historical recapture percentage $(\bar{p})$ and $(5)$ the observed recapture percentage for 1995.

3 Comparison of mean absolute deviances (MAD) for selected single streams for the entire observed 1994. 1995 outmigrations.

4 Comparison of mean absolute deviances (MAD) for selected single streams for the first half of the observed 1994.1995 outmigrations.

5 Comparison of mean absolute deviances (MAD) for selected single streams for the last half of the observed 1994.1995 outmigrations.

61995 passage dates (10\%.50\%.90\% and range) at Lower Granite Dam for PIT-tagged wild Snake River spring/summer chinook salmon smolts for the 13 individual streams used in the canposite and the composite run on the program RealTime based on the PIT-tagging of parr in 1994

\section{Appendix B}

Release-recapture $\chi^{2}$ tables for various sites for determination of homogeneity of recapture rates 


\section{PREFACE}

This project was initiated in 1993 in response to Endangered Species Act listings and the need for synthesis of biological information and development of new methodologies for inriver management to improve the protection of threatened and endangered stocks. Using the data provided from smolt monitoring and research projects, the Fish Passage Center and the Pacific States Marine Fisheries Commission PIT-Tag Information System (PTAGIS) primary database centers, and the second-tier University of Washington database support center DART (project 9601900), the focus was to develop statistical methods and software tools for the systematic inseason prediction of salmonid smolt outmigrations status and trends, as well as forecasting of the cumulative passage.

The initial version of the program RealTime (Skalski et al. 1994) used 1994 real-time PIT-tag detections at Lower Granite Dam to make daily predictions of the "percent run to date" and "date to specified percentiles" for a number of individual streams included in the NMFS ESU for wild Snake River spring/summer yearling chinook. In this first year, two experimental approaches, a synchronized historical run pattern matching algorithm and a least-squares algorithm, were compared to two algorithms in use by the Fish Passage Center (Townsend, et. al. 1995). Following the 1994 season, discussions with the technical staff of the Fish Passage Center and other parties resulted in combining the best aspects of all of the algorithms and an improved version of program RealTime was readied for the 1995 season (this report). The expansion of the RealTime program to include predictions for wild subyearling fall chinook salmonid smolt, based on the use of fish passage indices, was also developed and tested for the 1995 season (results not included in this report). For the1996 migration season, RealTiie is being integrated with the CRiSP project, to allow the prediction of smolt passage at other Snake and Columbia River dams from Little Goose to McNary Dams.

The predictions from these tools are provided interactively inseason, realtime to the fisheries community, including the National Marine Fisheries Service Technical Management Team committee via the World Wide Web to assist management of flow and spill augmentation to maximize benefits to smolt outmigration. Program RealTiie is available to all parties wishing to enhance monitoring and evaluation capabilities of their agency and of the fisheries community. 


\section{ACKNOWLEDGEMENTS}

We wish to express thanks to the many fisheries agencies and Tribes who have expended considerable resources in the generation, assembly, analysis and sharing of Columbia River PITtag information. Deserving particular thanks are the National Marine Fisheries Service, the nonfederal Smolt Monitoring Program agencies and Tribes, the Fish Passage Center and the Pacific States Marine Fisheries Commission PIT-Tag Information System (PTAGIS) primary database centers, and the second-tier University of Washington database support center DART (project 9601900). 


\section{Executive Summary}

Since 1988, wild salmon have been PIT-tagged through monitoring and research programs conducted by the Columbia River fisheries agencies and Tribes. Information from these studies is presented in reports by the Fish Passage Center (1994, 1995, 1996 in press), National Marine Fisheries Service (Accord et al. 1992, 1994, 1995a, 1995b, 1996), Idaho Department of Fish and Game (Kiefer et al. 1993, 1994), Oregon Department of Fish and Game (Walters et al. 1993, 1994a, Keefe et al. 1994b) and the Nez Perce Tribe (Ashe et al. 1995). The detection of tagged individuals at Lower Granite Dam provides a measure of the temporal and spatial distribution of the wild populations. PIT Forecaster was developed to take advantage of this historical data to predict the proportion of a particular population which had arrived at the index site in real-time and to forecast elapsed time to some future percentile in a migration.

The 1995 RealTime PIT Forecaster used an improvement in the 1994 Least Squares (IS) algorithm (Skalski et al. 1994, Townsend et al. 1995). denoted as the New Least Squares (NLS) prediction method. This report compares the new algorithm's performance with the 1994 PIT Forecaster predictions, and evaluates the 1995 overall run prediction effectiveness for individual streams and river composite.

The NLS method was applied to the 1994 outmigration for a direct comparison of the LS and NLS methods. For the 1994 spring/summer outmigration, the LS method gave an average error (mean average deviance (MAD)) of $11 \%$ over the entire run of the selected individual streams, with mean MADs of $13 \%$ and $11 \%$ for the first and last halves of the run. The NLS method gave a mean MAD for the selected individual streams of $4.3 \%$ for the entire 1994 run, with mean MADs of $5.7 \%$ and $3.9 \%$ for the first and last halves of the run. The new algorithm for 1995 thus improved performance by reducing the average error by over $50 \%$.

For the 1995 spring/summer outmigration, the NL,S method had a mean MAD of $6.4 \%$ for individual streams over the entire run, with average MADs of $7.1 \%$ and $6.1 \%$ for the first and last halves of the run respectively. The new river composite had a MAD of $2.2 \%$ over the entire run, with MADs $2.7 \%$ and $2.0 \%$ for the first and last halves of the run, indicating that though individual streams vary widely from each other and from year to year, there is a consistent pattern to the overall spring/summer smolt outmigration which the Realtime PIT-tag program is able to detect and use effectively in day-to-day predictions. 


\section{Introduction}

Three Ecologically Significant Units (ESU) of Pacific salmon (spring/summer Chinook fall chinook and sockeye salmon) have been designated as either threatened or endangered (T\&E) under the Endangered Species Act (ESA) in the Snake River Basin. The tributary populations of spring/summer chinook reside primarily in the Salmon and Grande Ronde drainages and Imnaha River, all of which are situated upstream of Lower Granite Dam. Additionally, a small population resides in the Tucannon River, which enters the Snake River between Lower Monumental and Little Goose dams. The sockeye reside in the uppermost portion of the main Salmon River in the Stanley Basin. Except for the Tucannon River population, all others reside upstream from Lower Granite Dam on the Snake River.

Regulating the timing and volume of water released from storage reservoirs (flow augmentation) has become a central mitigation strategy for improving downstream migration conditions for juvenile salmonids in the Snake River. Threatened and endangered salmon stocks have received increased priority with regard to the timing of this flow augmentation. The optimum is to release water from the storage reservoirs at times when the listed stocks are in geographic locations where they encounter the augmented flow.

In the Snake River Basin, regulated water enters the system at two locations, below Hell's Canyon Dam on the Snake River and below Dworshak Dam on the Clear-water River. The preponderance of regulated water available for fish passage is provided by Dworshak Reservoir. None of the listed stocks are located in the Clearwater drainage, and thus listed stocks must migrate to below the confluence of the Clearwater and Snake Rivers before they are fully exposed to augmented flows. The confluence forms the approximate upper boundary of the Lower Granite Reservoir Determining when stocks are in the vicinity of Lower Granite Dam and reservoir is a chief consideration in requesting flow augmentation.

Since 1988, wild salmon have been PIT-tagged through monitoring and research programs conducted by the Columbia River fisheries agencies and Tribes. Information from these studies is presented in reports by the Fish Passage Center (1994. 1995, 1996in press), National Marine Fisheries Service (Accord et al. 1992, 1994, 1995a. 1995b. 1996) Idaho Department of Fish and Game (Kiefer et al. 1993, 1994), Oregon Department of Fish and Game (Walters et al. 1993, 1994a, Keefe et al. 1994b) and the Nez Perce Tribe (Ashe et al. 1995). The detection of tagged individuals at Lower Granite Dam provides a measure of the temporal and spatial distribution of the wild populations. PIT Forecaster was developed to take advantage of this historical data to predict the proportion of a particular population which had arrived at the index site in real-time and to forecast elapsed time to some future percentile in a migration.

This report is a post-season analysis of the accuracy of the 1995 predictions from the program RealTime. Observed 1995 data were compared to the predictions made by RealTime for the spring outmigration of wild spring chinook observed at Lower Granite Dam through-out the season. Appendix C displays the graphical report capabilities of the RealTime program which were interactively accessible via the World Wide Web during the 1995 migration season. Final reports are still available at address http://www.cqs.washington.edu/rt/chinl-out.html. 


\section{M ethods}

\section{D escription of D ata}

The spring outmigration of wild spring chinook from thirteen individual streams were used in evaluating the 1995 performance of the New Least Squares (NLS) algorithms. These streams were chosen for their consistent recovery numbers, each having at least three years of data with a minimum of 30 detections per year. This was the minimum amount of historical data considered necessary in the formulation of the PIT Forecaster. A new inclusion for the 1995 season was the Grande Ronde, which did not have sufficient historical data for predictions prior to the 1995 season. River composites (Skalski, et al. 1994) were dropped from the program in favor of one overall river composite to better meet the requirements of river management.

\section{Table 1: The thirteen individual rivers used in evaluating the predictive performance of the PIT -F orecaster program.}

\begin{tabular}{ll}
\hline StreamName & epa-reach \\
\hline \hline Bear Valley Creek & 17060205 \\
BigCreek & 17060206 \\
Catherine Creek & 17060104 \\
ElkGeek & 17060205 \\
Grande Ronde River ${ }^{\mathrm{a}}$ & 17060106 \\
lmnaha River & 17060102 \\
Lostine River & 17060105 \\
Marsh Creek & 17060205 \\
Salmon River & 17060209 \\
Salmon River. East Fork & 17060202 \\
Salmon River, south Fork & 17060208 \\
Secesh River & $\mathbf{1 7 0 6 0 2 0 8}$ \\
Valley Creek & 17060201 \\
\hline
\end{tabular}

a. Grande Ronde available for 1995 predictions only.

The daily number of fish observed are adjusted for spill using a variant on a method suggested by Giorgi (1985) and Stuehrenberg (1986). For 20 and $40 \%$ of the total water volume going through the spillway at Lower Granite Dam, the suggested spill effectiveness was 41 and $61 \%$. respectively. A quadratic equation (1) approximates these two points of adjustment, as well as the points $(0,0)$ and $(1,1)$. This interpolation is compared to a one-to-one conversion in Fig. 1.

$$
\text { spilleff }=\text { spillvol } \times(2.583+\text { spillvol } \times(\text { spillvol } \times 1.667-3.25))
$$

where: spilleff $=$ spill efficiency, and

spillvol = total water volume going through the spillway. 
Figure 1: R ealT ime spill adjustment compared to a one-to-one conversion.

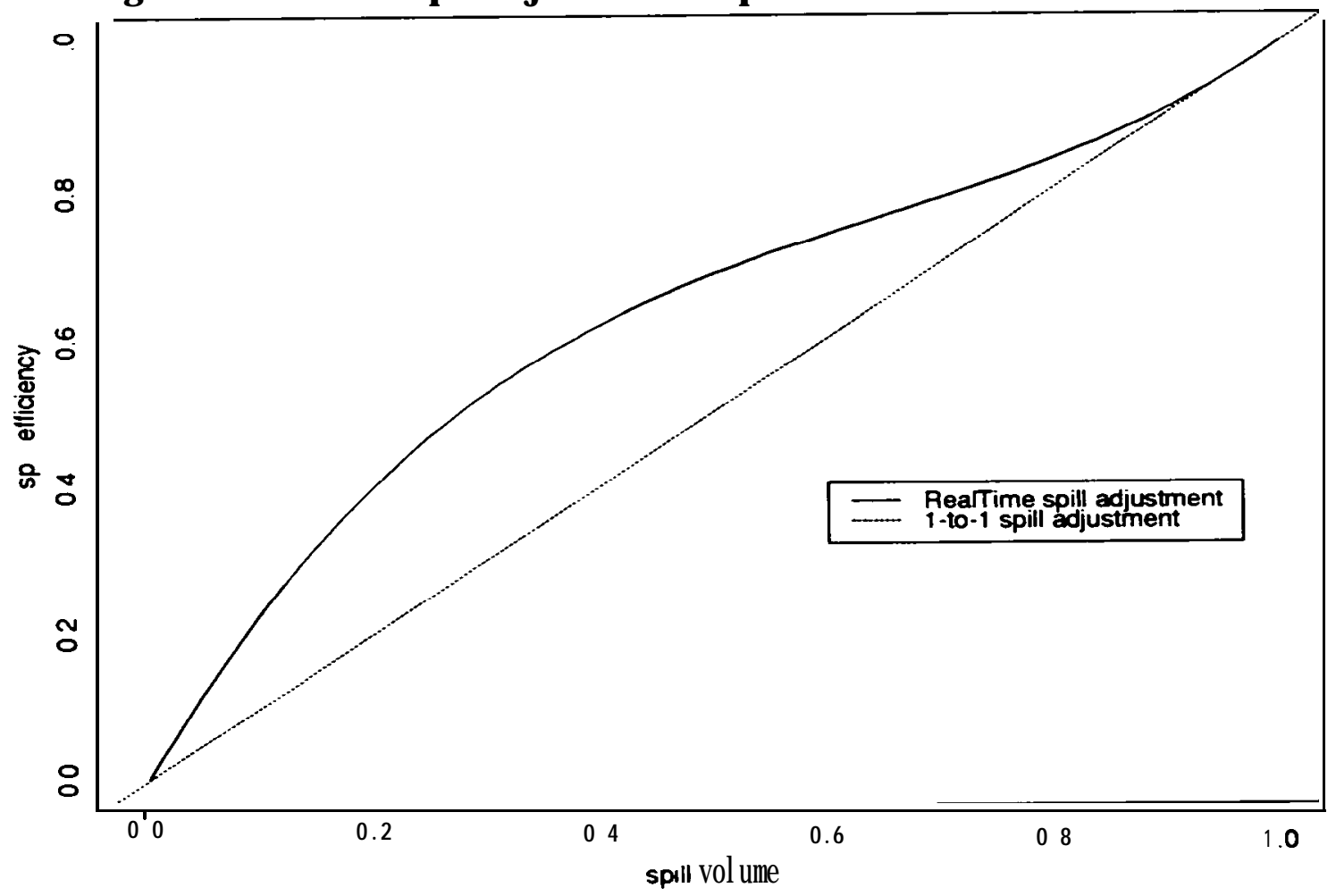

\section{Prediction M odels}

In the 1994 post-season analysis of Realtime (Townsend et al. 1995), two alternative methods were suggested as bench-mark comparisons to the 1994 Least Squares prediction method. Alternative \#l to the LS method made a prediction of run timing by using the total recapture proportion observed in a previous season and then assuming that proportion to be consistent for the present year. For Alternative \#2, the prediction was the historical proportion observed on a given day of outmigration for a specified historical year. The New Least Squares (NLS) method is a variation of the Least Squares (LS) prediction method used for the 1994 season, incorporating releaserecapture information (or other external pre-run estimates) and an improved measure of the age of the run (using the mean fish-run-age vice the raw age of the run) into its prediction analysis. This effectively binds versions of Alternative methods \#1 and \#2 and the 1994 Least Squares method together into a single, more accurate and robust predictor.

\section{$\underline{\text { New Least-Squares (NLS) Algotithm }}$}

For a given day in the run, the NLS algorithm computes the predicted percentage $(\hat{p})$ of the outmigration by finding the value of fi that minimizes the estimated error according to historical run data. The $\hat{p}$ error is a weighted combination of the least-squares (LS) error, the release-recapture (RR) error, and the age-of-run (AR) error. Weighting depends on the age of the run and the quality of the historic data for the given stream. In the 1994 post-season analysis, the releaserecapture method was shown to be a better predictor at the beginning of a run, deteriorating as 
time progressed. On the other hand, the least-squares method started poorly, but became a better predictor as the run progressed. To combine these two methods, the release-recapture algorithm prediction is heavily weighted initially, with weight shifted to the LS method over time. The initial weighting of the RR error also depends on the consistency of release-recapture history for the selected stream or river composite.

\section{Least-Squares (LS) Error}

The least squared error (LSE) for each $\hat{p}$ is summed over the historical years for which data are available. Each outmigration pattern is divided into 100 equal portions and the slopes at each corresponding point are computed. The sum of squares for a prediction compares the slopes for the current year $\left(s_{o j}\right)$ versus the respective slopes for the historical years $\left(s_{i j}\right)$. The total squared error for each predicted percentage of outmigration $\hat{\boldsymbol{p}}$ is calculated according to the formula

$$
\operatorname{LSE}(\hat{p})=\sum_{i=1}^{n} \sum_{j=0}^{\hat{p}}\left(s_{o j}-s_{i j}\right)^{2} w_{i}
$$

where $s_{o j}=$ observed slope at the $j$ th percentile $(j=0, \ldots, p)$ for the current year of prediction, $s_{i j}=$ slope at the $j$ th percentile $(j=0, \ldots, \mathrm{p})$ for the ith historical year $(i=1, \ldots, n)$, and $\mathbf{w}_{i j}=$ weight for the $j$ th percentile for the $i$ th historical year.

For example, letting $\hat{p}=30 \%$. the present run will be compared to the first $30 \%$ of the outmigration for each historical year. Similar calculations are performed for each percentage from 0 to 100 percent. The percentage that minimizes the sum of squares (Eq. 2) is the best prediction for the current outmigration timing according to the LS algorithm. The weighting factor is included to more evenly distribute the squared error contribution throughout the outmigration distribution. The weights are

$$
\mathfrak{u}_{i j}=\frac{D_{o j}+D_{i j}}{R_{o}+R_{1}}
$$

where $D_{o j}=$ estimated number of days between the $(j-1)$ and $j$ th percentile for the present year, $D_{i j}=$ number of days between the $(j-1)$ and $j$ th percentile for the $i$ th historical year $(i=1$, .., n),

$R, \quad=$ range in days of the current observed outmigration, and

$\boldsymbol{R}_{\boldsymbol{i}} \quad=$ range in days of the ith historical year outmigration $(i=1, \ldots, n)$.

The effect of $w_{i j}$ is to give more weight to the errors generated from the tails of the distribution, where the slopes tend to be flat and the number of days between each percentile point are high. Less weight is given to the mid-season, where large slopes are more likely. The total sum of the weights adds to one. 


\section{R elease-R ecapture (R R) Error}

Alternative \#l made predictions of run timing by using the total recapture proportion observed in a previous season and then assuming that proportion to be consistent for the present year. Further analysis of the recapture-recovery proportions show that this number is not homogeneous through the years for all streams (Appendix B), so the average proportion ( $\bar{p}$ ) for an individual stream is used. The predicted percent of the run is calculated according to the formula

$$
p_{R R}=\frac{x_{d}}{\bar{p} \times N}
$$

where

$p_{R R}=$ estimated proportion of the outmigration passed on day $\mathrm{d}$,

$x_{d}=$ total observed smolt to day $d$,

$p \quad=$ mean total proportion of outmigration recovered, and

$\mathbf{N}=$ total number of smolt tagged for the present year.

The number of fish tagged for the present year for a given stream or stream aggregate is multiplied by the mean recapture ratio $(\bar{p})$ of previous years (Table 2 ) to determine the total number of fish expected. The proportion passed is then estimated. For example, Valley Creek observed an mean recapture ratio of 3.83\% at Lower Granite Dam over the years 1989 to 1994 . For the 1995 run, 1552 smolt were released in Valley Creek. The expected total number of smolt for 1995 based on historical data would be 59.44 smolt $(1552 * 0.0383)$.

RealTime then evaluates each possible percentage $\hat{\boldsymbol{p}}$ ( 0 to 100 ) by calculating an associated Release-Recapture error (RRE). The RRE is the ratio of alternative \#l's prediction $p_{R R}$ and each percentage $\hat{\boldsymbol{p}}$ :

$$
\operatorname{RRE}(\hat{p})=\left\{\begin{array}{cl}
\frac{\hat{p}}{p_{R R}} & \text { if } \hat{p}>p_{R R} \\
\frac{p_{R R}}{\hat{p}} & \text { if } \hat{p}<p_{R R} \\
1 & \text { if } \hat{p}=p_{R R}
\end{array}\right.
$$

The prediction $\hat{p}$ is assigned the least amount of error $(R R E(\hat{p})=1)$ when it is equal to the alternative \#l prediction $p_{R R}$ and more error $(R R E(\hat{p})>1)$ the further $\hat{p}$ is from $p_{R R}$. 
Table 2: Summary for the thirteen streams used in the 1995 evaluation of the PITForecaster program showing (1) wild chinook salmon parr released in 1994, (2) detected number of smolts at Lower Granite Dam in 1995, (3) number of years of historical data, $(4)$ average historical recapture percentage $(\vec{p})$ and $(5)$ the observed recapture percentage for 1995.

\begin{tabular}{|c|c|c|c|c|c|}
\hline Tagging Location & $\begin{array}{l}(1) \\
\text { Parr Tagged } \\
1994\end{array}$ & $\begin{array}{l}\text { (2) } \\
\text { Smolt PIT detections } \\
\text { Lower Granite D am } \\
1995\end{array}$ & $\begin{array}{c}\text { (3) } \\
\text { Number of years } \\
\text { historical data }\end{array}$ & $\begin{array}{l}\text { (4) } \\
\text { Average historical } \\
\text { recapture } \\
\bar{p} \text { vi) }\end{array}$ & $\begin{array}{c}(5) \\
1995 \\
\text { recapture } \\
p^{a}(\%)\end{array}$ \\
\hline Bear Valley Creek & 1460 & 74 & 5 & 8.28 & 5.07 \\
\hline Big Creek & 1484 & 164 & 5 & 7.73 & 11.05 \\
\hline Catherine Creek & 2061 & 202 & 4 & 7.98 & 9.80 \\
\hline Elk Creek & 1514 & 76 & 5 & 8.21 & 5.02 \\
\hline Grande Ronde & 1898 & 169 & 3 & 7.97 & 8.90 \\
\hline Imnaha River & 999 & 40 & 6 & 7.83 & 4.00 \\
\hline Lostine River & 1008 & 112 & 5 & 9.66 & 11.11 \\
\hline Marsh Creek & 1590 & 103 & 5 & 8.51 & 6.48 \\
\hline Salmon River & 1217 & 19 & 5 & 7.61 & 1.56 \\
\hline Salmon River East Fork & 986 & 69 & 5 & 5.15 & 7.00 \\
\hline Salmon River South Fork & 1574 & 78 & 5 & 7.81 & 4.96 \\
\hline secesh River & 1551 & 90 & 6 & 7.49 & 5.80 \\
\hline Valley Creek & 1552 & 50 & 6 & 3.83 & 3.22 \\
\hline
\end{tabular}

a. Data Sources PTAGIS Database and RealTime program output as of 6 December 1995.

\section{Age-of-R un (AR) Error}

For Alternative \#2 in last year's analysis, the prediction $\hat{p}$ was the historical proportion observed on a given day of outmigration for a specified historical year.

$$
\hat{p}=p_{y d}
$$

where $p_{y d}=$ proportion of outmigration passed on day $d$ for historical year $y$.

For a given day of run, the proportion predicted is given by the proportion observed in the index year on that day of the run (e.g. for a run estimated to be in its 15th day. the percentage passed by day 15 in a historical run is the estimated present percentage observed). This method was very unstable as historical patterns did not support a day-for-day matching in smolt migration through the years. On the other hand, the mean age of the run, weighted by the cumulative number of fish 
observed per day, appeared to offer further information and be more robust year to year. The mean fish-run-age (MFRA) is calculated for each $p$ of the last historical outmigration and the present run by

$$
\operatorname{MFRA}(p)=\frac{\sum_{d=1}^{n}\left[\text { fish }_{d} \times(n+1-d)\right]}{\sum_{d=1}^{n} \text { fish }_{d}}
$$

where:

$$
\begin{aligned}
f i s h_{d}= & \text { number of fish observed on day d, } \\
n= & \text { total number of days until the cumulative proportion } p \text { of the total smolt outmi- } \\
& \text { gration has been observed. }
\end{aligned}
$$

The present year's MFRA is matched to each historical year's MFRA. The historical observed $p$ corresponding to the matching MFRA is the predicted $p_{A R}$ from that year.

The Age-of-Run error associated with this prediction (ARE) is the ratio of the present run mean fish-run-age $\left(M F R A_{A R}\right)$ and the predicted percentage $\hat{p}$ mean fish-run-age $\left(M F R A_{\hat{p}}\right)$ :

$$
A R E(\hat{p})=\left\{\begin{array}{cl}
\frac{M F R A_{\hat{p}}}{M F R A_{A R}} & \text { if } M F R A_{j}>M F R A_{A R} \\
\frac{M F R A_{A R}}{M F R A_{\hat{p}}} & \text { if } M F R A_{\hat{p}}<M F R A_{A R} \\
1 & \text { if } M F R A_{\hat{p}}=M F R A_{A R}
\end{array}\right.
$$

This gives the prediction from the AR algorithm the least amount of error, with more error the further $\hat{p}$ is from $p_{A R}$.

\section{Calculation of the Total E rror}

An error is computed for each $\hat{\boldsymbol{p}}(0-100)$ by combining the three algorithms by

$$
\operatorname{Err}(\hat{p})=\left(1+\frac{L S E}{L S E \times M F R A+200.0}\right) \times\left(1+\left[\frac{100}{M F R A^{2}+p_{R R} \times 16} \times R R E\right]^{2}\right) \times\left(1+\frac{A R E}{50.0}\right)
$$

where:

$A R E \quad=$ age-of-run error for $\hat{p}$ from Eq. 6 ,

$L S E \quad=$ least squares error for $\hat{p}$ from Eq. 1,

$M F R A=$ mean fish-run-age for the present run from Eq. 5,

$p \quad=$ predicted proportion of observed present smolt outmigration, and

$R R E=$ release-recapture error for $\hat{p}$ from Eq. 3 . 
The MFRA in Eq. 6 also serves the purpose of shifting weighting of the errors from the releaserecapture algorithm to the least-squares algorithm as the age of the run increases. The constants were found by heuristically adjusting the equation and observing program prediction performance for historical outmigration data. The program selects the $\hat{p}$ with the minimal calculated error.

\section{Calculation of Comparison Scores}

The results presented in Tables 3 through 5 contain the mean absolute deviance (MAD) of the NLS and LS predictions for each stream from the observed 1994 data and the NLS predictions of the observed 1995 data. The MAD is calculated by the formula

$$
M A D=\frac{\sum_{i=1}^{n}\left|\hat{p}_{i}-p_{i}\right|}{n}
$$

where $\hat{p}_{i}=$ predicted cumulative percentage of run completed for day $\mathrm{i}$,

$p_{i}=$ observed cumulative percentage of run completed for day $\mathrm{i}$, and

$n=$ total number of days in run for 1994 season.

The methods are compared three ways: the MAD over the entire run, the MAD over the first half of the run (i.e. cumulative run to the 50\%), and the MAD over the last half of the run.

\section{R esults}

The 1994 and 1995 NLS method prediction results reveal that the modifications to the 1994 LS method dramatically improved the accuracy of the PIT Forecaster. In Table 3, we see that the 1994 NLS method prediction performance (mean MAD 4.3\%) is much better than the performance of the 1994 LS method (mean MAD 11\%). In 1995 the NLS method also performed well (6.4\%). Tables 4 and 5 compare the performance of the predictors over the first and last halves of the run, respectively. Graphs of the daily RealTime predictions versus individual observed runs are in Appendix A.

In 1995, a composite run, an average of the daily predictions of our thirteen individual streams, was substituted in place of last year's aggregate predictions. The predictions for this composite proves to be extremely reliable and accurate throughout the run when compared to the observed run composite. Figure 2 compares the day-to-day composite predictions and confidence intervals with the observed composite run for the year. Figure 3 and Table 6 compare the ten, fifty and ninety percent-passage dates of the individual stocks/streams with the program RealTime composite dates. While the predictive performance of the composite works well to indicate status of the composite, some individual streams fall out of its predicted percentage passage dates. This is to be expected, as the composite does not weight the run estimate by stock, but by the total 
arrival pattern observed. Smaller runs will have less effect on this pattern, and may thus have part of their perspective run percentages outside of the indicated percentages. Using distances calculated from the release tables in the DART database via "DART PIT-tags observed by release site" , the two release sites furthest from Lower Granite Dam had an arrival distribution much later than the majority of releases (Figure 3), but the third farthest release site, East Fork Salmon River, arrived before the composite, so distance alone cannot account for the timing of arrival.

Figure 2: D ay-to-day predictions and the daily confidence intervals compared to the observed run for 1995 season.

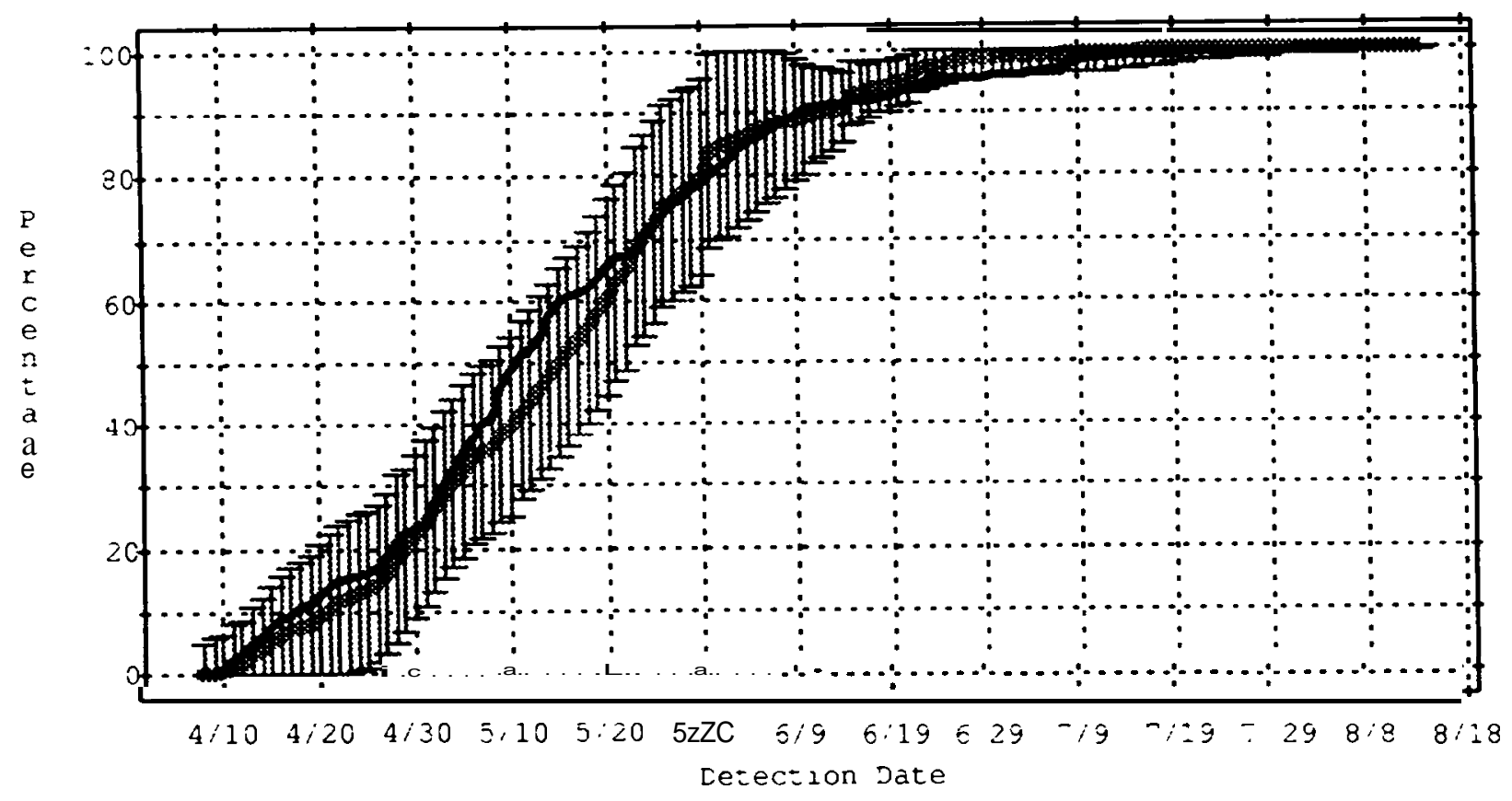

Dalisy pred.

Curc Pred

1. World Wide Web address: http://www.cqs.washington.edu/dart/pit_rel_de.html. Data courtesy of Pacific States Marine Fisheries Commission. 
Table 3: Comparison of mean absolute deviances (M AD) for selected single streams for the entire observed 1994, 1995 outmigrations.

\begin{tabular}{lccc}
\hline Tag Site & 1994LS & 1994 NLS & 1995 NLS \\
\hline Bear Valley Creek & .08 & .040 & .045 \\
Big Creek & .20 & .052 & .029 \\
Catherine Creek & .06 & .036 & .056 \\
Elk Creek & .08 & .040 & .066 \\
Grande Ronde River & --- & --- & .064 \\
lmnaha River & .11 & .034 & .100 \\
Lostine River & .06 & .029 & .035 \\
Marshcreek & .07 & .030 & .049 \\
Salmon River & .30 & .059 & .155 \\
Salmon River East Fork & .10 & .067 & .046 \\
Salmon River South Fork & .05 & .013 & .087 \\
Secesh River & .17 & .087 & .028 \\
Valley Creek & .06 & .035 & .073 \\
composite run & ----- & .001 & .022 \\
\hline \hline mean MAD & .11 & .043 & 0.064 \\
median MAD & .08 & .038 & 0.049 \\
range & $.05-.30$ & $.013-.087$ & $.028-.155$ \\
\hline
\end{tabular}


Table 4: Comparison of mean absolute deviances (MAD)for selected single streams for the first half of the observed 1994, 1995 outmigrations.

\begin{tabular}{lccc}
\hline Tag Site & 1994 LS & 1994 N L & 1995 NLS \\
\hline Bear Valley Creek & .15 & .116 & .056 \\
Big Creek & .14 & .050 & .061 \\
Catherine Creek & .09 & .043 & .027 \\
Ek Creek & .15 & .068 & .082 \\
Grande Ronde River & ----- & ---- & .050 \\
lmnaha River & .18 & .048 & .155 \\
Lostine River & .14 & .024 & .034 \\
Marsh Creek & .11 & .093 & .078 \\
Salmon River & .21 & .083 & .131 \\
Salmon River East Fork & .09 & .035 & .070 \\
Salmon River South Fork & .04 & .016 & .086 \\
Secesh River & .13 & .046 & .038 \\
Valley Creek & .16 & .065 & .051 \\
composite run & ----- & .012 & .027 \\
\hline \hline mean MAD & .13 & .057 & .071 \\
median MAD & .14 & .049 & .061 \\
range & $.04-.21$ & $.016-.116$ & $.027-.155$ \\
\hline
\end{tabular}


Table 5: Comparison of mean absolute deviances (M AD) for selected single streams for the last half of the observed 1994, 1995 outmigrations.

\begin{tabular}{lccc}
\hline Tagging Site & 1994 LS & 1994NL-S & 1995 NLS \\
\hline Bear Valley Creek & .06 & .015 & .039 \\
Big Creek & .21 & .052 & .015 \\
Catherine Creek & .05 & .034 & .066 \\
Elk Creek & .07 & .034 & .058 \\
Grade Ronde River & ---- & --- & .076 \\
Imnaha River & .10 & .031 & .077 \\
Lostine River & .04 & .030 & .036 \\
Marsh Creek & .06 & .020 & .036 \\
Salmon River & .31 & .058 & .161 \\
Salmon River East Fork & .11 & .074 & .035 \\
Salmon River South Fork & .05 & .012 & .087 \\
Secesh River & .17 & .088 & .025 \\
Valley Creek & .05 & .024 & .089 \\
composite run & .06 & .014 & .020 \\
\hline \hline meanMAD & $.04-.31$ & $.012-.088$ & $.025--161$ \\
medianMAD & & .039 & .061 \\
range & .11 & .032 & .058 \\
\hline
\end{tabular}


Figure 3: 1995 passage dates (10\%, 50\%, 90\% and range) at Lower G ranite Dam for PITtagged wild Snake R iver spring/summer chinook salmon smolts for the 13 individual streams used in the composite and the composite run of program R ealTime. based on the PIT-tagging of parr in 1994. The dashed lines shows the $95 \%$ coverage by R ealT ime's composite of the individual streams. Distances calculated from the release tables in the DART database via "D AR T PIT-tags observed by release site"

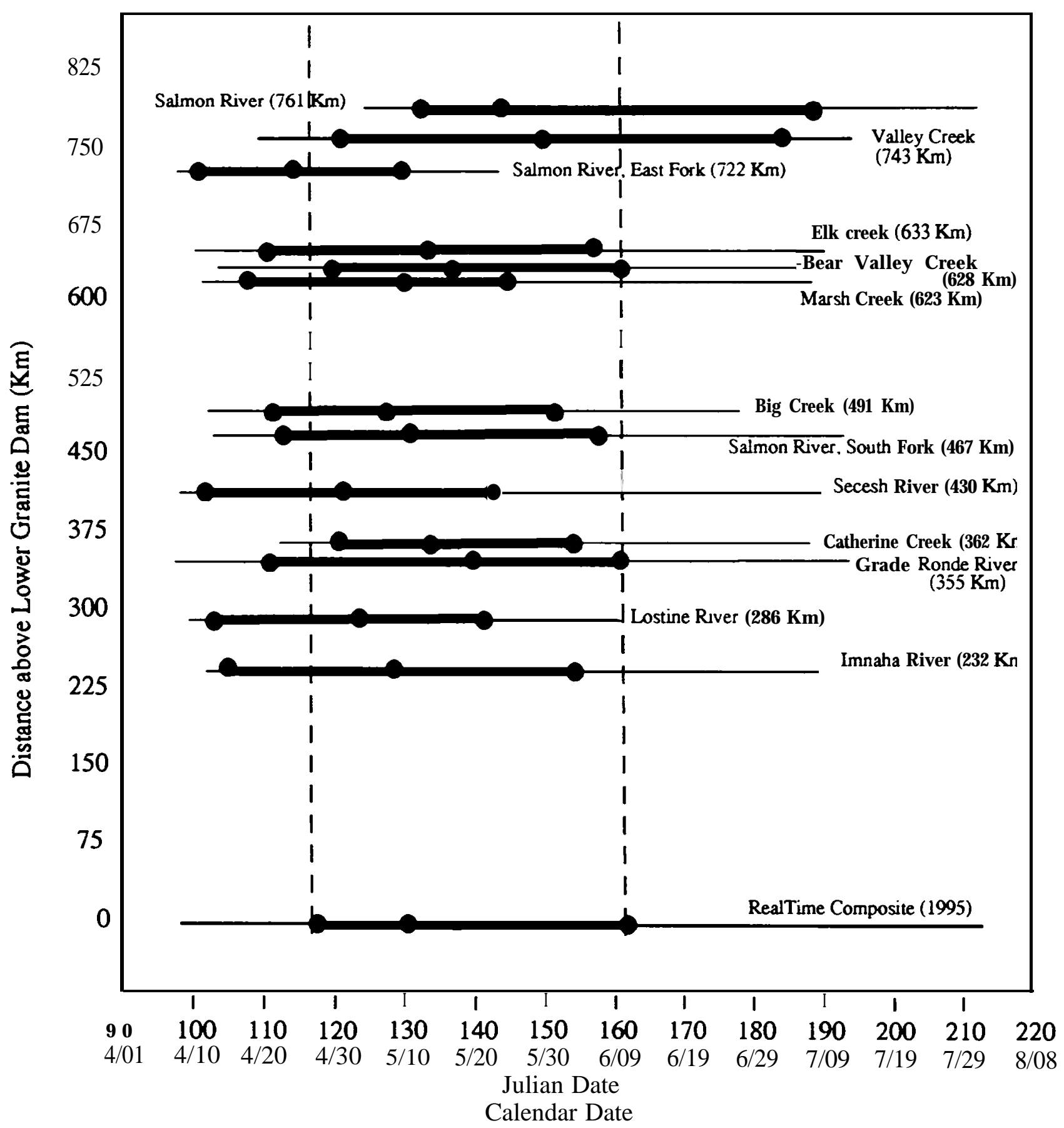


Table 6: 1995 passage dates ( $10 \% 50 \%, 90 \%$ and range) at Lower Granite D am for PIT-tagged wild Snake R iver spring/summer chinook salmon smolts for the 13 individual streams used in the composite and the composite run on the program R ealTime, based on the PIT-tagging of parr in 1994.

\begin{tabular}{|c|c|c|c|c|}
\hline \multirow[b]{2}{*}{ population or stock } & \multicolumn{4}{|c|}{ Passage Dates at Lower Granite Dam } \\
\hline & $10 \%$ & $50 \%$ & $90 \%$ & Range \\
\hline Bear Valley Creek & 3OApril & 18 May & 10 June & 13 April - 20 July \\
\hline Big Creek & 21 April & 07May & 30May & 11 April-08 July \\
\hline Catherine Creek & 01 May & 13 May & 05 June & 22 April - 08 July \\
\hline Elk Creek & 20 April & 13 May & 06 June & 1OApril-09July \\
\hline Grande Ronde River & 2OApriJ & 19 May & 09 June & 12 April - 01 July \\
\hline Imnaha River & 13Apri.1 & 08 May & 02 June & 10 April - 07 July \\
\hline Lostine River & 12 April & 03 May & 20 May & 08 April-09 June \\
\hline Marsh Creek & 17 April & 10 May & 24May & 11 April - 08 July \\
\hline Salmon River & 13 May & 25 May & 09 July & 06 May - 01 August \\
\hline Salmon River, East Fork & 12 April & 28 April & 1 May & 11 April - 27 May \\
\hline Salmon River, South Fork & 24 April & 11 May & 09 June & 13 April - 13 July \\
\hline Secesh River & 12 April & 03 May & 26 May & 10 April - 10 July \\
\hline Valley Creek & 04 May & 02 June & 07 July & 22 April - 18 July \\
\hline Program Real Time Composite & 18 April & 10 May & 07 June & 08 April - 01 August \\
\hline
\end{tabular}




\section{Discussion}

The results from the 1995 season show that the modifications proposed in the 1994 post-season analysis dramatically improved the Realtime prediction performance. The composite gives the additional tool of predicting run-status of the selected streams foral run at Lower Granite Dam. Unfortunately, this composite is not a catch-all single number which can be used to quantify the individual stock run-status. Stocks must be looked at separately to gain a complete picture (Appendix $\mathrm{C}$ displays the graphical report capabilities of the RealTime program). A graphical daily comparison of each individual stream and river with RealTime predictions (Appendix A) reenforces the program's accuracy in per stock run predictions. Low spring/summer chinook spawner abundance and production in many streams and drainages of the Snake River system in 1995 reduced the number of streams where adequate numbers of par-r could be marked with PIT

tags, likely decreasing the effectiveness of the composite run of the RealTime Forecaster program in outmigration year 1996. Future development of the RealTime program will include integration capabilities with the CRISP project to allow forecasts to be projected down-river of the Lower Granite Dam. 


\section{Literature Cited}

Achord. S., M.B. Eppard, B.P. Sandford and G.M. Matthews. 1996. Monitoring the migrations of wild Snake River spring/summer chinook salmon smolts, 1995. National Marine Fisheries Service, Seattle, Washington. Annual Report 1995 (DOE/BP-18800-4) to Bonneville Power Administration, Project 91-028, Contract DE-AI79-91BP18800. 179p.

Achord, S., J.R. Harmon, D.M. Marsh, B.P. Sandford, K.W. McIntyre, K.L. Thomas, N.N. Paasch and G.M. Matthews. 1992. Research Related to Transportation of Juvenile Salmonids on the Columbia and Snake Rivers, 1991. National Marine Fisheries Service, Seattle, Washington.

Achord, S., G.M. Matthews, D.M. Marsh, B.P. Sandford and D.J. Kamikawa. 1994. Monitoring the migrations of wild Snake River spring and summer chinook salmon smolts, 1992. National Marine Fisheries Service, Seattle, Washington. Annual Report 1992 (DOE/BP-18800-1) to Bonneville Power Administration, Project 91-028, Contract DE-AI79-91BP18800.73 p.

Achord, S., D.J. Kamikawa, B.P. Sanford and G.M. Matthews. 1995a. Monitoring the migrations of wild Snake River spring/summer chinook salmon smolts 1993. National Marine Fisheries Service, Seattle, Washington. Annual Report 1993 (DOE/BP-18800-2) to Bonneville Power Administration, Project 91-028, Contract DE-AI79-91BP18800.88 p.

1995b. Monitoring the migrations of wild Snake River spring/summer chinook salmon smolts, 1994. National Marine Fisheries Service, Seattle, Washington. Annual Report 1994 (DOE/BP-18800-3) to Bonneville Power Administration, Project 91-028, Contract DE-AI79-91BP18800. $100 \mathrm{p}$.

Ashe, B.L., A.C. Miller, P.A. Kucera and M.L. Blenden. 1995. Spring Outmigration of Wild and Hatchery Chinook Salmon and Steelhead Trout Smolts from Imnaha River, March 1 - June 15, 1994. Nez Perce Tribe, Department of Fisheries Resources Management, Lapwai, Idaho. Technical Report to Bonneville Power Administration DOE/BP-38906-4 - December 1995.76 p.

Fish Passage Center of the Columbia Basin Fish and Wildlife Authority: 1994. 1993 Annual Report to Bonneville Power Administration Project 94-033 DOE/BP-38906-3 - April1994. 123 p. plus appendices.

Fish Passage Center of the Columbia Basin Fish and Wildlife Authority: 1995. 1994 Annual Report to Bonneville Power Administration Project 94-033.77 p. plus appendices.

Fish Passage Center of the Columbia Basin Fish and Wildlife Authority: 1996 (in press). 1995 Annual Report to Bonneville Power Administration Project 94-033.

Giorgi, A.E., L.C. Stuehrenberg, D.R. Miller and C.W. Sims. 1985. Smolt passage behavior and flow-net relationship to the forebay of John Day Dam. Final Res. Rep. to Bonneville Power Administration, Portland, OR. 68 p. (Available from National Marine Fisheries Center, CZES Division, 2725 Montlake Blvd. E., Seattle, WA 98112.) 
Keefe, M.L., R.W. Carmichael, B.C. Jonasson, R.T. Messmer and T.A. Whitesel. 1994b. Investigations into the Life History of Spring Chinook in the Grande Ronde River Basin. Annual Report, 1994: Fish Research Project, Oregon Department of Fish and Wildlife. Report to Bonneville Power Administration.

Kiefer, R.B. and J.N. Lockhart. 1993. Idaho Habitat and Natural Production Monitoring: Part II. Idaho Department of Fish and Game - Fisheries Research Section. Annual Report to Bonneville Power Administration DOE/BP-2 1182-2 - October 1993. 67 p.

1994. Intensive Evaluation and Monitoring of Chinook Salmon and Steelhead Trout Production, Crooked River and Upper Salmon River Sites. Idaho Department Fish and Game -- Fisheries Research Section. Annual Report to Bonneville Power Administration DOE/BP-21 182-5 - May 1995. 70 p.

Skalski J.R., G. Tartakovsky, S.G. Smith and P. Westhagen. 1994. Pre-1994 Season Projection of Run-Timing Capabilities Using PIT-tag Databases. Center for Quantitative Science, School of Fisheries, University of Washington, Seattle, Washington. Technical Report to Bonneville Power Administration Project 9 1-05 1 DOE/BP-35885-7 - April 1996.67 p.

Stuehrenberg, L.C., A.E. Giorgi, C.W. Sims, J. Ramonda-Powel and J. Wilson. 1986. Juvenile radio-tag study: Lower Granite Dam. Final Res. Rep. to Bonneville Power Administration, Portland, OR. 68 p. (Available from National Marine Fisheries Center, CZES Division, 2725 Montlake Blvd. E., Seattle, WA 98112.)

Townsend. R.L., P. Westhagen, D. Yasuda and J.R. Skalski. 1995. Evaluation of the 1994 Predictions of the Run-Timing of Wild Migrant Yearling Chinook in the Snake River Basin. Center for Quantitative Science, School of Fisheries, University of Washington, Seattle, Washington. Technical Report to Bonneville Power Administration Project 91-05 1 DOE/BP-35885-7 - April 1996.93 p.

Walters, T.R., R.W. Carmichael and M.L. Keefe. 1993. Smolt Migration Characteristics and Mainstem Snake and Columbia River Detection Rates of PIT-tagged Grande Ronde and Imnaha River Naturally Produced Spring Chinook Salmon. Annual Progress Report, 1993: Fish Research Project, Oregon Department of Fish and Wildlife. Report to Bonneville Power Administration, 42 P-

1994a. Smolt Migration Characteristics and Mainstem Snake and Columbia River Detection Rates of PIT-tagged Grande Ronde and Imnaha River Naturally Produced Spring Chinook Salmon. Annual Progress Report, 1993: Fish Research Project, Oregon Department of Fish and Wildlife. Report to Bonneville Power Administration, 57 p. 


\section{Appendix A}

Performance Plots for the 1995 Outmigration Season

R ealT ime Plots 


\section{PIT Forecaster: Bear Valley Creek}

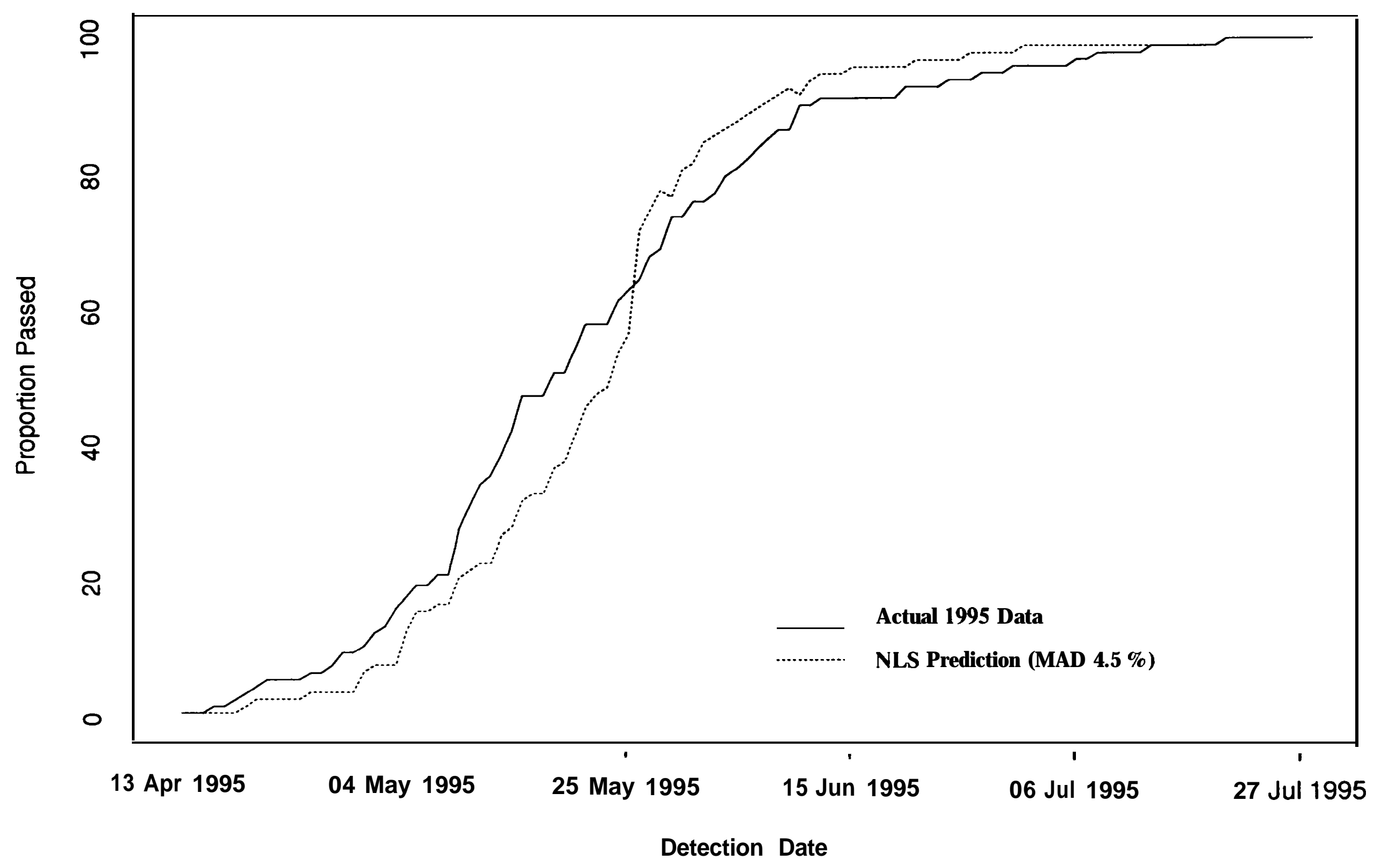




\section{PIT Forecaster: Big Creek}

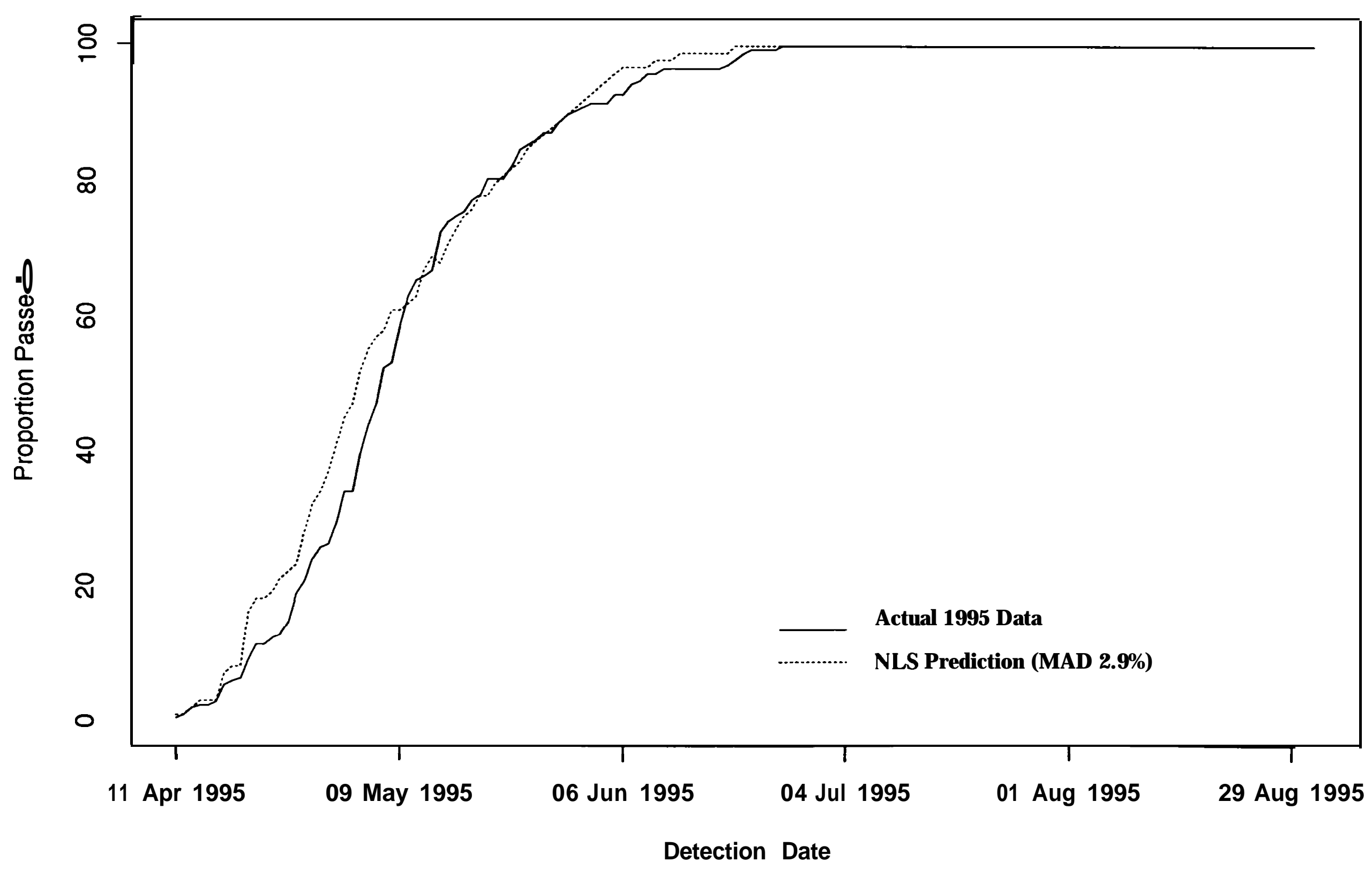




\section{PIT Forecaster: Elk Creek}

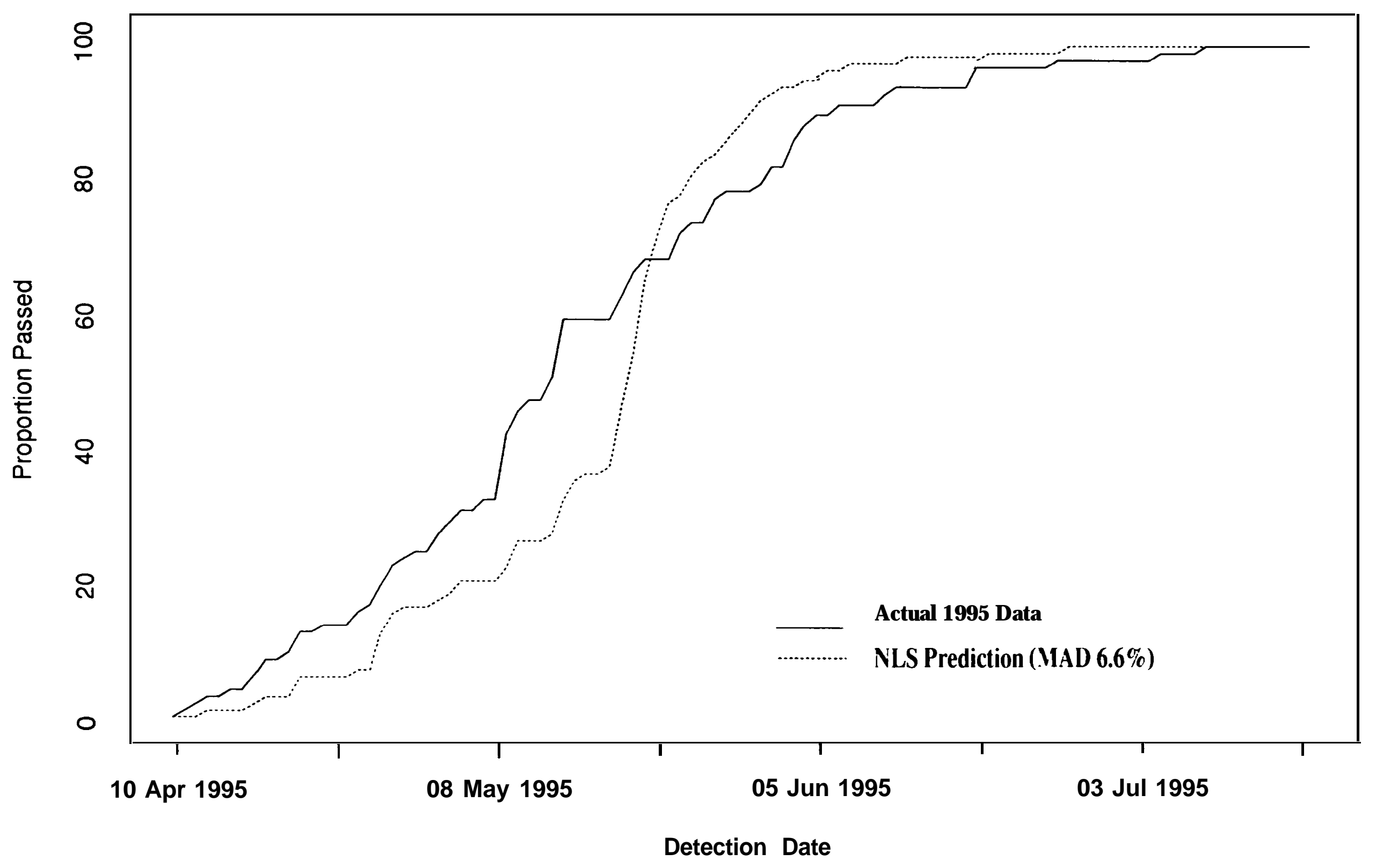




\section{PIT Forecaster: Lostine River}

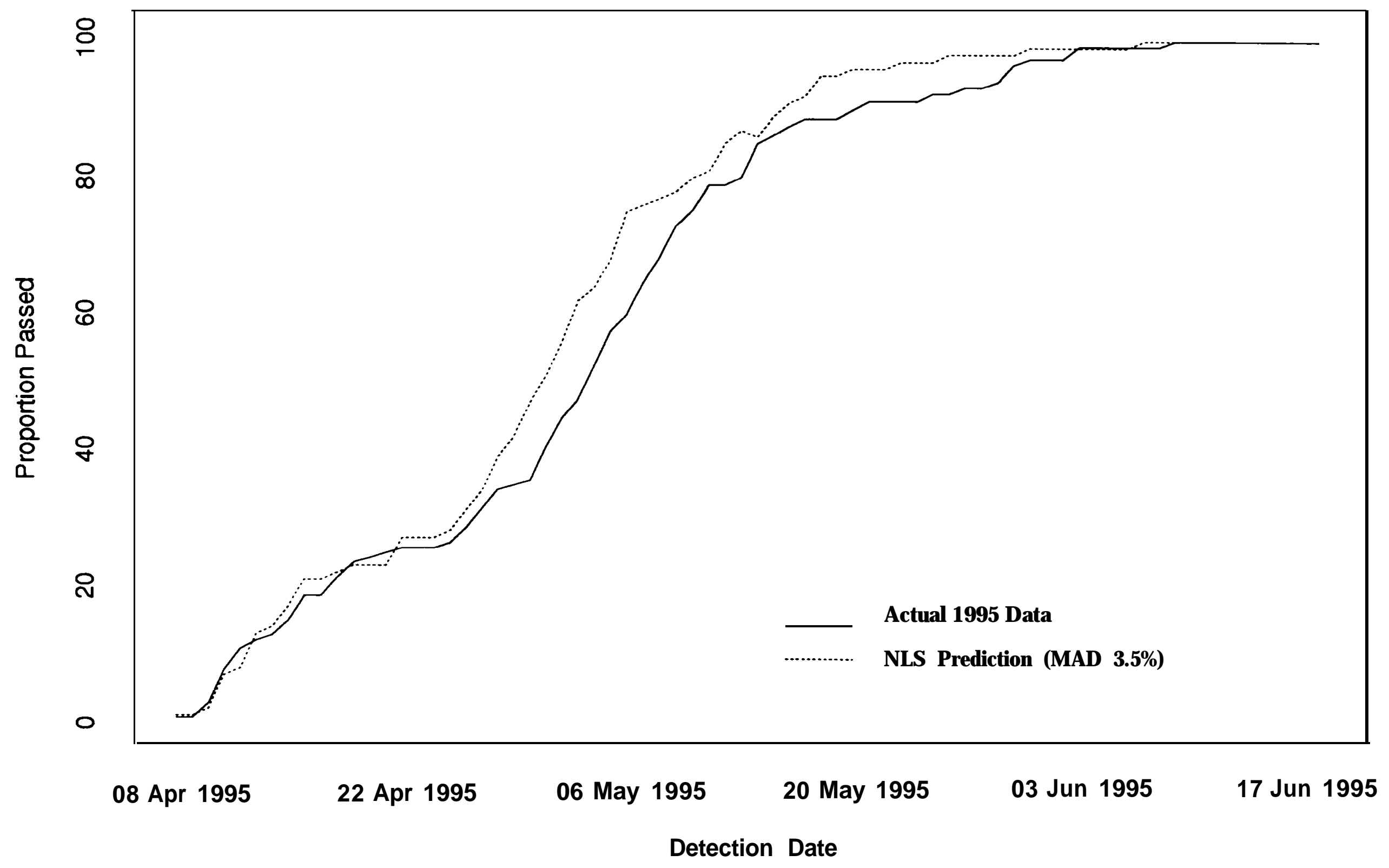




\section{PIT Forecaster: Marsh Creek}

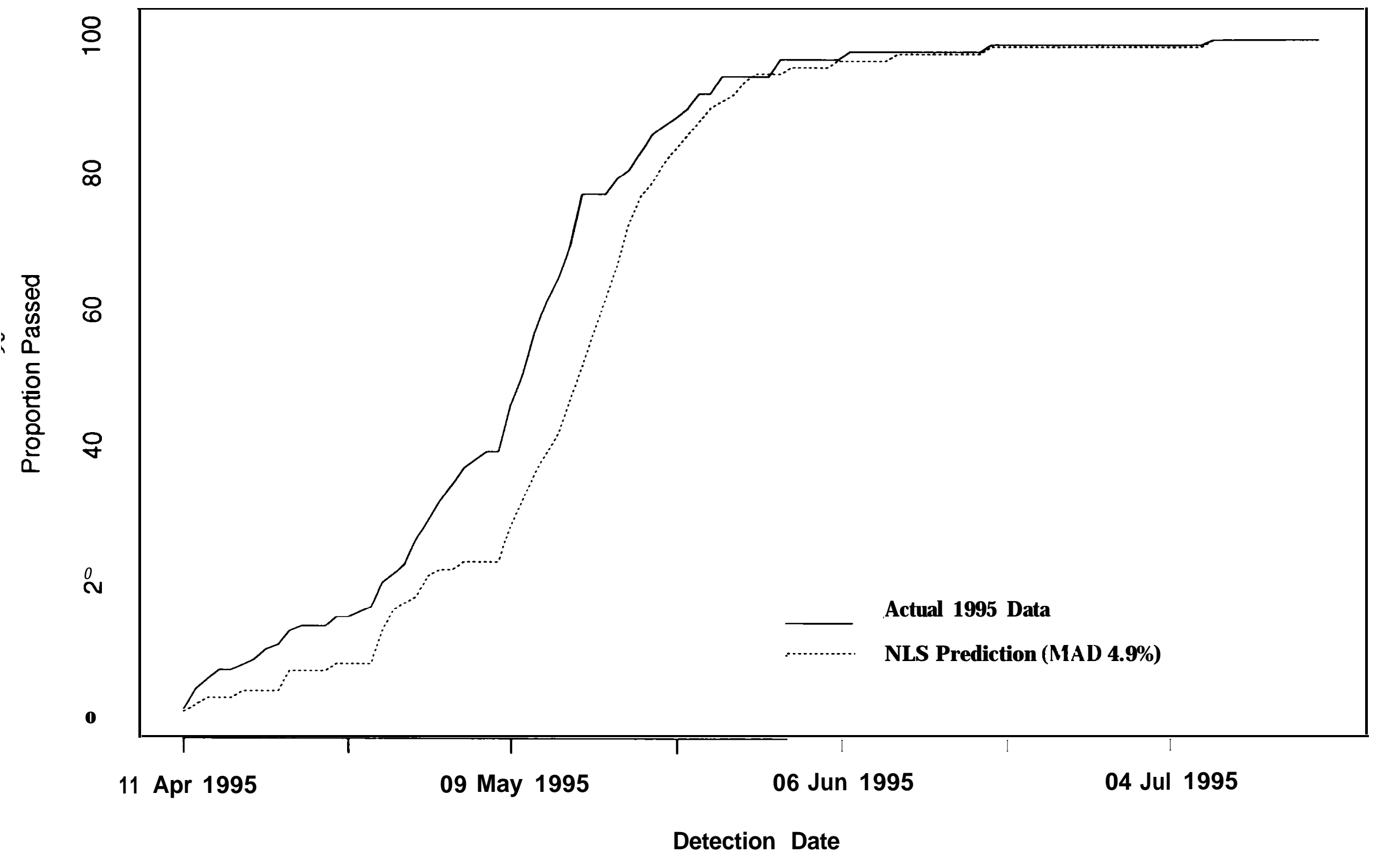




\section{PIT Forecaster: Salmon River}

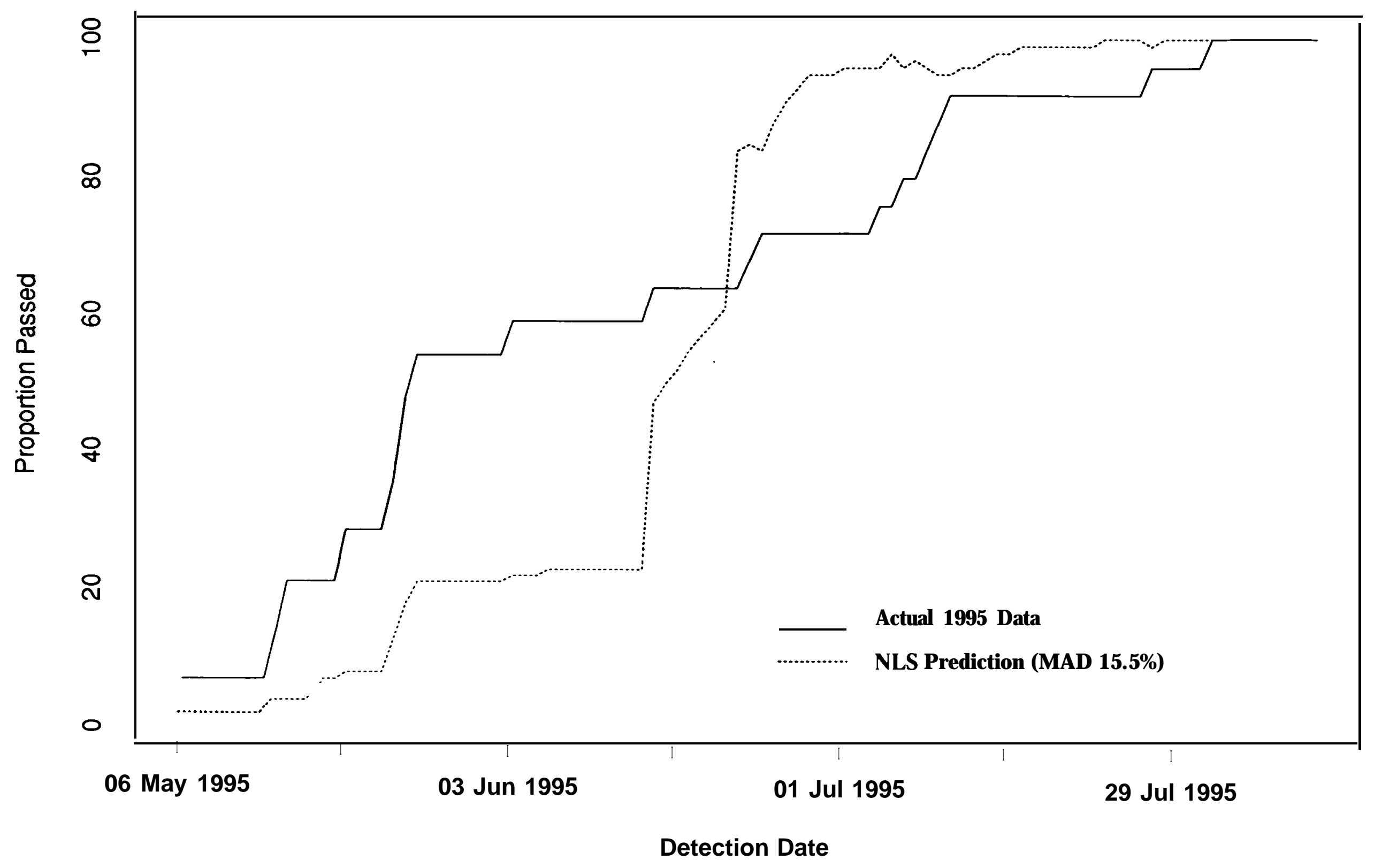




\section{PIT Forecaster: Salmon River East Fork}

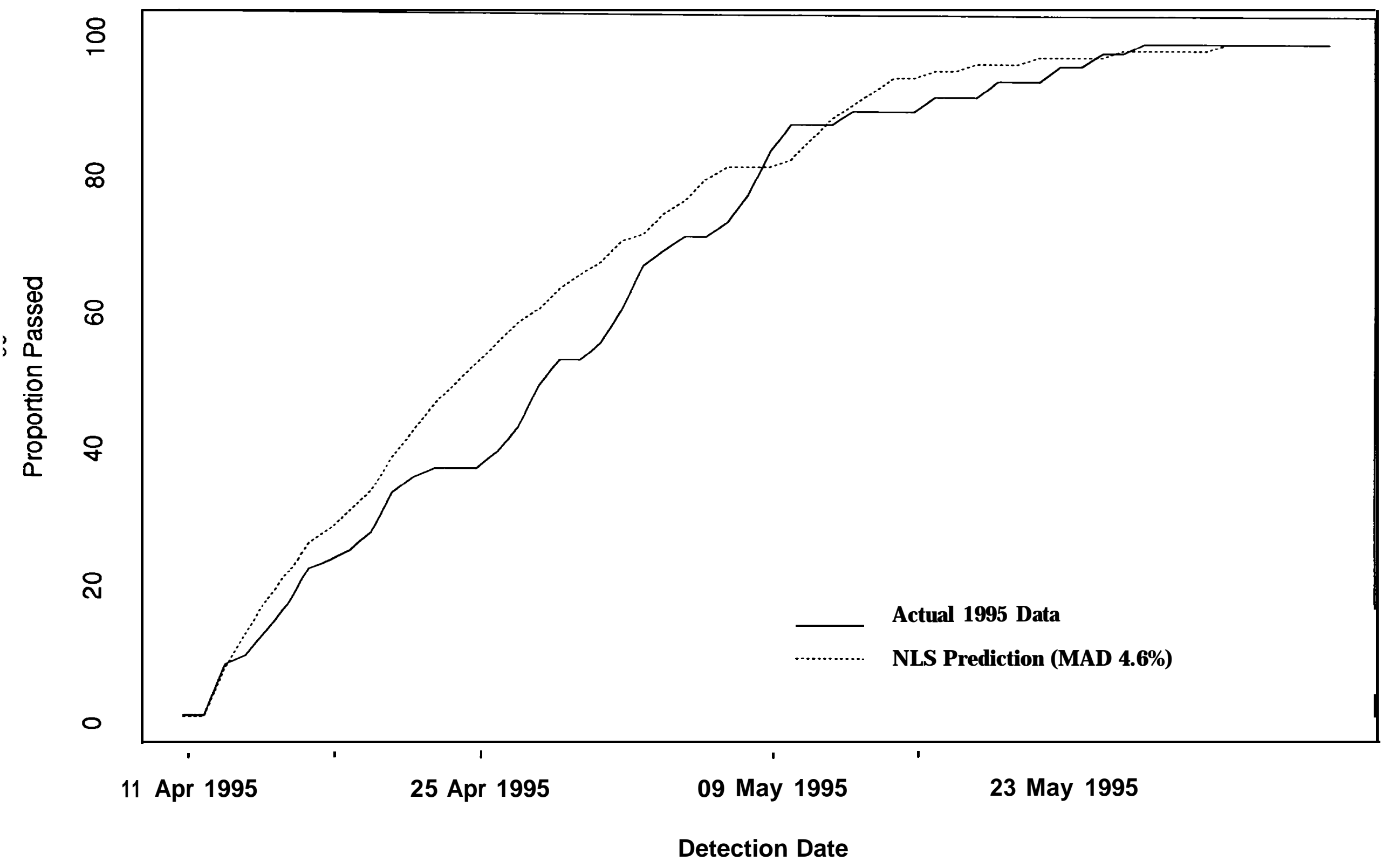




\section{PIT Forecaster: Salmon River South Fork}

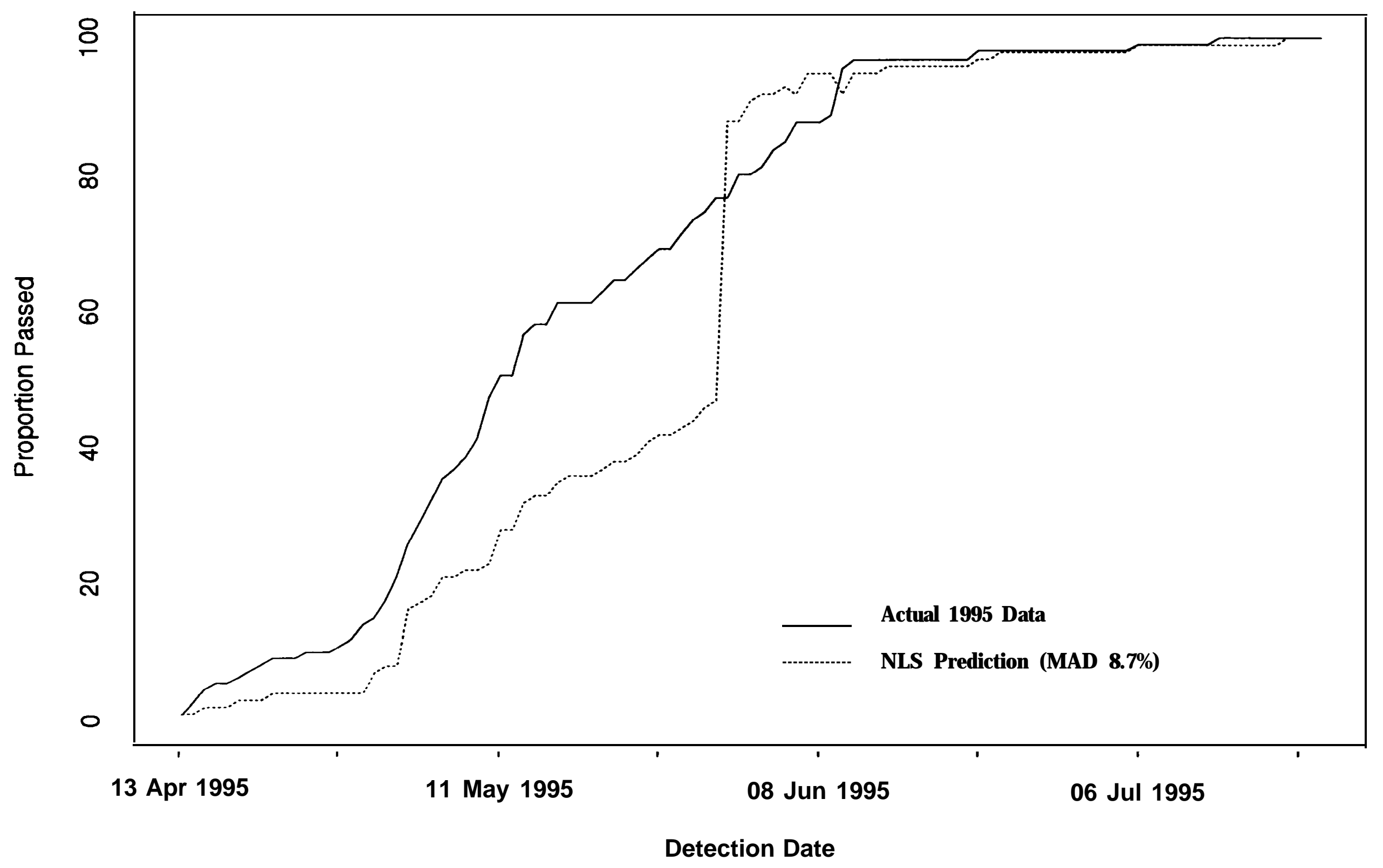




\section{PIT Forecaster: Secesh River}

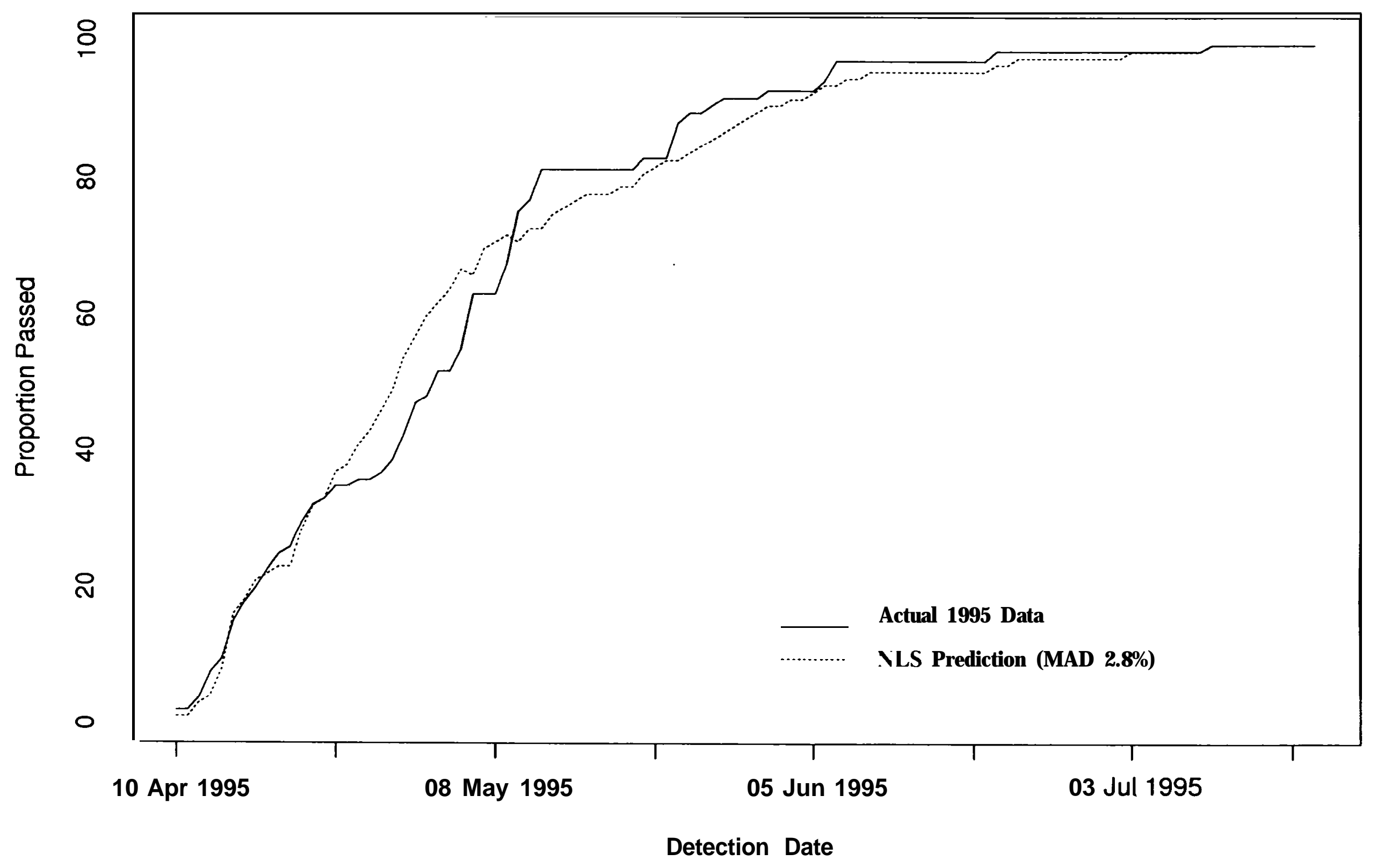




\section{PIT Forecaster: Composite Summary}

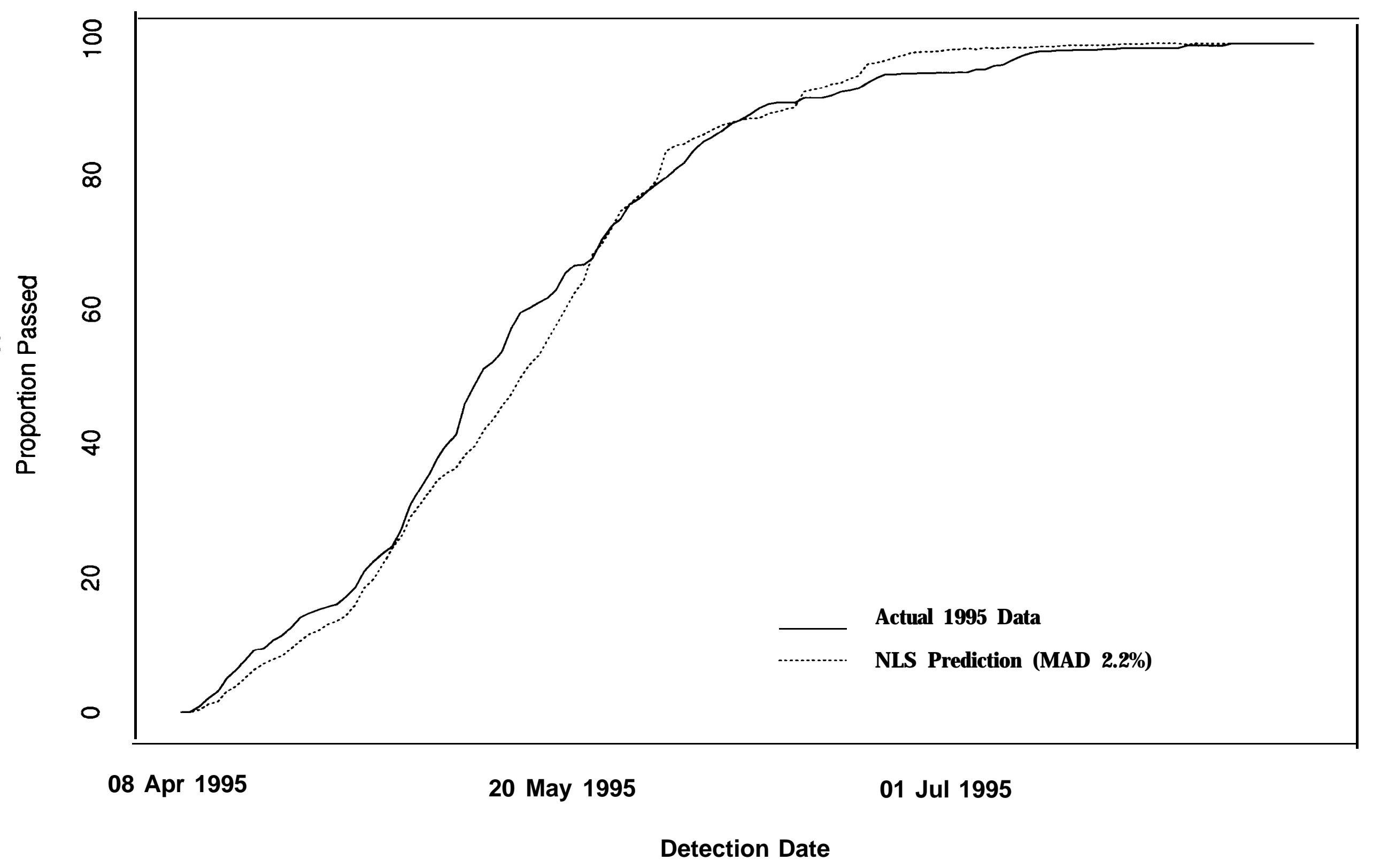




\section{Appendix B}

\section{Comparison of Historical Recovery Rates}

The historical release and recovery rates of PIT-tagged spring/summer chinook smolt in the Snake River Basin were investigated as result of findings from the 1994 post-season performance report of the Realtime PIT-Forecaster program. This simple assumption that recovery rates from streams are consistent was explored, and the analysis determined that a useful prediction algorithm may be derived for the first half of the migration run. The release count for each year was categorized into "detecld" and "not detected" recoveries and then tested for homogeneity between years with a $x$ test of homogeneity. If the test had a p value of 0.10 or less, the years were significantly heterogeneous and an average recovery rate $(\bar{p})$ was calculated. A pooled recovery rate $\left(p_{p}\right)$ was determined for the streams found to be homogeneous. Twenty-one of the 59 sites were homogenious, suggesting that this prediction method would work for only a few areas. $\bar{p}$ and $p_{p}$ were calculated using the formulas

$$
\bar{p}=\frac{\sum_{i=\mathbf{1 9 8 9}}^{1994} p_{i}}{n}
$$

where $p_{i}=$ proportion of released smolt detected for year $i(i=1989, \ldots$ 1994), pi $=$ NA (missing value) if no data available,

$n=$ number of years with available data, and

$$
p_{p}=\frac{\sum_{i=1989}^{1994} d_{i}}{\sum_{\mathrm{j}=1989}^{1994} R_{j}}
$$

where $d_{i}=$ number of detected smolt for year $i$, and

$R j=$ number of smolt released for yearj.

These $\mathrm{p}$ and $p_{p}$ were then used in the Realtime algorithms for the 1995 season forecasts. The following tables show the data used to calculate the individual stream recapture rates, the test of homogeneity of the available data for 1989-1994, and the predicted $p$ based on historical data for 1995. 


\section{$R$ elease sites used by the $R$ eal $T$ ime program}

Release Site: Bear Vallev Creek (BEARVC) (spring chinookl

O bservation Site: Lower Granite J uvenile (GR J)

Migration Year:

89

$90 \quad 91$

92

$93 \quad 94$

95

Detected:

Not detected:

91

44

69

1429

309

1284

67

950

None $\quad 1557$

353

1044

1017

85

74

Released:

Probability of

Detection:

$$
0.0584
$$

0.1246

0.0661

0.0659

$0.0988 \quad 0.0507$

$\chi^{2} \mathrm{p}$ value $<0.0001, \bar{p}=0.0828$

\section{O bservation Site: Snake R iver Trap J uvenile (SNJ)}

Migration Year:

89

90

$91 \quad 92$

93
$94 \quad 95$

Detected:

Not detected:

Released:

$\begin{array}{rrrrrrr} & 0 & 1 & 1 & 3 & 1 & 0 \\ & 1557 & 352 & 1043 & 1014 & 859 & 1460 \\ \text { None } & 1557 & 353 & 1044 & 1017 & 860 & 1460\end{array}$

Probability of

Detection:

$\begin{array}{lllll}0 & 0.0028 & 0.0010 & 0.0029 & 0.0012\end{array}$

0

$\chi^{2} p$ value $=0.2752, p_{p}=0.0012$

\section{Release Site: Big Creek (BIGC) (soring chinook)}

O bservation Site:L ower G ranite J uvenile (GRJ)

$\begin{array}{llllllll}\text { Migration Year: } & 89 & 90 & 91 & 92 & 93 & 94 & 95\end{array}$

$\begin{array}{lrrrrrr}\text { Detected: } & 148 & 67 & 57 & 65 & 55 & 164\end{array}$

$\begin{array}{lllllll}\text { Not detected: } & 1887 & 660 & 951 & 668 & 667 & 1320\end{array}$

$\begin{array}{llllllll}\text { Released: } & \text { None } & 2035 & 727 & 1008 & 733 & 722 & 1484\end{array}$

Probability of

$\begin{array}{lllllll}\text { Detection: } & 0.0727 & 0.0922 & 0.0565 & 0.0887 & 0.0762 & 0.1105\end{array}$

$\chi^{2} \mathrm{p}$ value $=0.0376, \bar{p}=0.0773$ 
O bservation Site: Snake R iver Trap J uvenile (SN J)

$\begin{array}{llllllll}\text { Migration Year: } & 89 & 90 & 91 & 92 & 93 & 94 & 95\end{array}$

$\begin{array}{lrrrrrr}\text { Detected: } & 0 & 1 & 0 & 2 & 0 & 1\end{array}$

$\begin{array}{lllllll}\text { Not detected: } & 2035 & 726 & 1008 & 731 & 722 & 1483\end{array}$

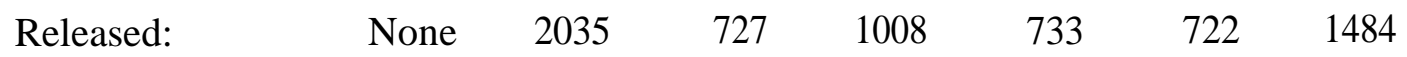

Probability of

$\begin{array}{lllllll}\text { Detection: } & 0 & 0.0014 & 0 & 0.0027 & 0 & 0.0007\end{array}$

$\chi^{2} \mathrm{p}$ value $=0.0635, \bar{p}=0.0008$

Release Site: Catherine Creek (CATHEC) (sprine chinook)

O bservation Site: Lower G ranite J uvenile (GR J )

$\begin{array}{llllllll}\text { Migration Year: } & 89 & 90 & 91 & 92 & 93 & 94 & 95\end{array}$

$\begin{array}{llllll}\text { Detected: } & 79 & 67 & 102 & 76 & 202\end{array}$

$\begin{array}{llllll}\text { Not detected: } \quad 935 & 873 & 1006 & 924 & 1859\end{array}$

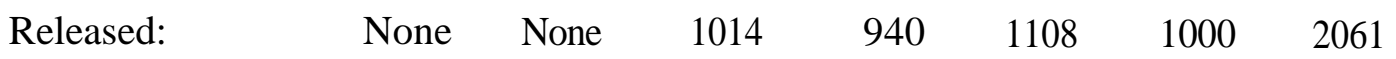

Probability of

Detection:

$\begin{array}{lllll}0.0779 & 0.0713 & 0.0921 & 0.0760 & 0.0980\end{array}$

$\chi^{2} \mathrm{p}$ value $=0.3280, p_{p}=0.0798$

O bservation Site: Snake R iver Trap J uvenile (SN J)

$\begin{array}{llllllll}\text { Migration Year: } & 89 & 90 & 91 & 92 & 93 & 94 & 95\end{array}$

Detected: $\quad \begin{array}{rrrrr}0 & 0 & 1 & 0 & 1\end{array}$

Not detected: $\quad 1014 \quad 940 \quad 1107 \quad 1000 \quad 2060$

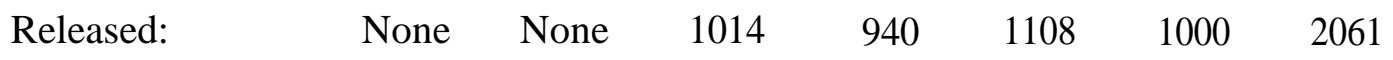

Probability of

Detection:

$\begin{array}{lllll}0 & 0 & 0.0009 & 0 & 0.0005\end{array}$

$\chi^{2} \mathrm{p}$ value $=0.4459, \boldsymbol{p}_{p}=0.00 \mathrm{Q} 2$ 


\section{Release Site: Elk Creek (ELKC) (spring chinook)}

\section{O bservation Site: Lower G ranite J uvenile (GR J )}

Migration Year:

89

$90 \quad 91 \quad 92$

93

$94 \quad 95$

Detected:

Not detected:

Released:

$\begin{array}{rrr} & 1 & 32 \\ \text { None } & 15 & 216 \\ 16 & 248\end{array}$

36
426

42

586

$74 \quad 76$

462

628

$925 \quad 1438$

$999 \quad 1514$

Probability of

Detection:

$$
0.0625
$$

0.1290

0.0779

0.0669

0.0741

0.0502

$\chi^{2} \mathrm{p}$ value $=0.0366, \quad \bar{p}=0.0821$

O bservation Site: Snake River Trap J uvenile (SNJ)

Migration Year:

89

90

91

92

$93 \quad 94 \quad 95$

Detected:

Not detected:

Released:

None

$0 \quad 0$

$\begin{array}{rrrr}0 & 1 & 0 & 0 \\ 462 & 627 & 999 & 1514 \\ 462 & 628 & 999 & 1514\end{array}$

Probability of

Detection:

$0 \quad 0$

0.0016

$0 \quad 0$

$\chi^{2} \mathrm{p}$ value $=0.6008, \quad p_{p}=0.0004$

\section{Release Site: Grande Ronde River (GRANDR) (spring chinook)}

O bservation Site: Lower G ranite J uvenile (GR J )

\begin{tabular}{|c|c|c|c|c|c|c|c|}
\hline Migration Year: & 89 & 90 & 91 & 92 & 93 & 94 & 95 \\
\hline Detected: & 244 & & & & 89 & 136 & 169 \\
\hline Not detected: & 2750 & & & & 875 & 1791 & 1729 \\
\hline Released: & 2994 & None & None & None & 964 & 1927 & 1898 \\
\hline $\begin{array}{l}\text { Probability of } \\
\text { Detection: }\end{array}$ & 0.0815 & & & & 0.0923 & 0.0706 & 0.0890 \\
\hline
\end{tabular}




\section{Release Site: Imnaha River (IMNAHR)_(summer_chinook)}

\section{O bservation Site: Lower G ranite J uvenile (GR J )}

Migration Year:

89

$$
90
$$

$$
91
$$

92

93

94

95

Detected:

Not detected:

$\begin{array}{rr}73 & 161 \\ 1140 & 1844 \\ 1213 & 2005\end{array}$

18
316
334

$\begin{array}{rrrr}73 & 63 & 204 & 40 \\ 686 & 940 & 1549 & 954 \\ 759 & 1003 & 1753 & 999\end{array}$

Probability of

Detection:

$$
0.0602 \quad 0.0803
$$

$$
0.0539
$$

0.0962

0.0628

0.1164

0.0400

$\chi^{2} \mathrm{p}$ value $<0.0001, \bar{p}=0.0783$

O bservation Site: Snake R iver Trap J uvenile (SN J)

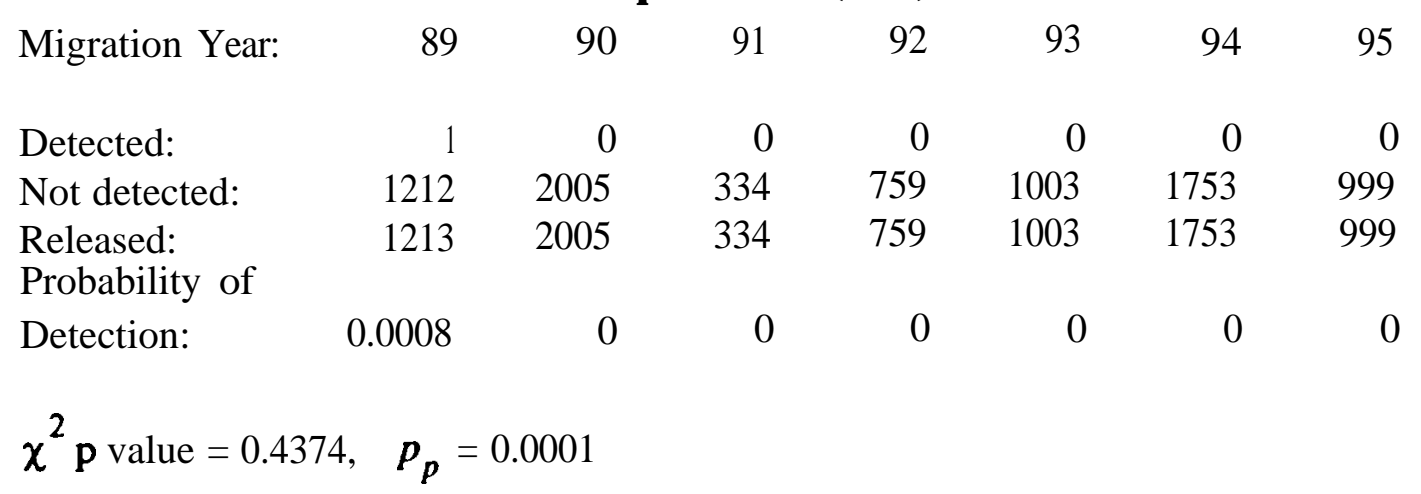

Release Site:_Lostine River (LOSTIR)_(spring_chinook)

O bservation Site: L ower G ranite J uvenile (GR J )

$\begin{array}{lrrrrrrr}\text { Migration Year: } & 89 & 90 & 91 & 92 & 93 & 94 & 95 \\ & & & & & & & \\ \text { Detected: } & & 8 & 90 & 93 & 123 & 69 & 112 \\ \text { Not detected: } & & 76 & 927 & 1014 & 893 & 664 & 896 \\ \text { Released: } & \text { None } & 84 & 1017 & 1107 & 1016 & 733 & 1008\end{array}$

Probability of

$\begin{array}{lllllll}\text { Detection: } & 0.0952 & 0.0885 & 0.0840 & 0.1211 & 0.0941 & 0.1111\end{array}$

$\chi^{2} \mathrm{p}$ value $=0.0444, \bar{p}=0.0966$ 


\section{O bservation Site:S nake R iver Trap J uvenile (SNJ)}

$\begin{array}{lrrrrrrr}\text { Migration Year: } & 89 & 90 & 91 & 92 & 93 & 94 & 95 \\ & & & & & & & \\ \text { Detected: } & & 0 & 0 & 0 & 0 & 0 & 0 \\ \text { Not detected: } & & 84 & 1017 & 1107 & 1016 & 733 & 1008 \\ \text { Released: } & \text { None } & 84 & 1017 & 1107 & 1016 & 733 & 1008\end{array}$

Probability of

Detection:

0

$0 \quad 0$

0

$0 \quad 0$

$\chi^{2} \mathrm{p}$ value $=\mathrm{NA}, \bar{p}=0.00$

\section{Release Site: Marsh Creek (MARSHC) (soring chinook1}

\section{O bservation Site:L ower G ranite J uvenile (GR J)}

Migration Year:

89

90

91

92

93

94

95

Detected:

179

59

67

$82 \quad 500$

103

Not detected:

2338

802

$914 \quad 918 \quad 3190$

1487

Released:

None 2517

861

$981 \quad 1000 \quad 3690$

1590

Probability of

Detection:

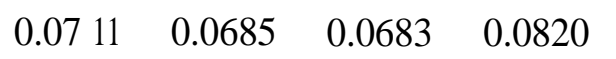

$0.1355 \quad 0.0648$

$\chi^{2} \mathrm{p}$ value $<0.0001, \bar{p}=0.0851$

O bservation Site: Snake R iver Trap J uvenile (SN J)

Migration Year:

$$
89
$$

90

91

92

93

94

95

Detected:

Not detected:

Released:

$\mathbf{0}$
2517
None $\quad 2517$

0
861
861

$\begin{array}{rrrr}0 & 1 & 8 & 0 \\ 981 & 999 & 3682 & 1590 \\ 981 & 1000 & 3690 & 1590\end{array}$

Probability of

Detection:

$0 \quad 0$

$\begin{array}{lll}0 & 0.0010 & 0.0022\end{array}$

0

$\chi^{2} \mathrm{p}$ value $=0.0507, \bar{p}=0.0006$ 


\section{Release Site: Salmon River (SALR) (sprino chinook)}

O bservation Site: L ower G ranite J uvenile (GR J )

$\begin{array}{llllllll}\text { Migration Year: } & 89 & \mathbf{9 0} & 91 & 92 & 93 & 94 & 95\end{array}$

$\begin{array}{lllllll}\text { Detected: } & 103 & 3 & 61 & 38 & 46 & 19\end{array}$

$\begin{array}{lllllll}\text { Not detected: } & 555 & 24 & 2238 & 1543 & 693 & 1198\end{array}$

$\begin{array}{llllllll}\text { Released: } & 658 & \text { none } & 27 & 2299 & 1581 & 739 & 1217\end{array}$

Probability of

$\begin{array}{lllllll}\text { Detection: } & 0.1565 & 0.1111 & 0.0265 & 0.0240 & 0.0622 & 0.0156\end{array}$

$\chi^{2} \mathrm{p}$ value c $0.0001, \bar{p}=0.0761$

O bservation Site: Snake R iver Trap J uvenile (SN J)

$\begin{array}{llllllll}\text { Migration Year: } & 89 & \mathbf{9 0} & 91 & 92 & 93 & 94 & 95\end{array}$

\begin{tabular}{|c|c|c|}
\hline Detected: & 0 & 0 \\
\hline Not detected: & 658 & 1217 \\
\hline Released: & 658 & 1217 \\
\hline
\end{tabular}

Probability of

Detection:

0

0

$0 \quad 0.0006$

0

0

$\chi^{2}$ p value $=0.6707, p_{p}=0.0002$

\section{Release Site: Salmon River East Fork(SALREF)_spring_chinook)}

0 bservation Site: Lower G ranite J uvenile (G R J )

Migration Year:

89

$90 \quad 91$

92

$93 \quad 94 \quad 95$

Detected:

Not detected:

Released:

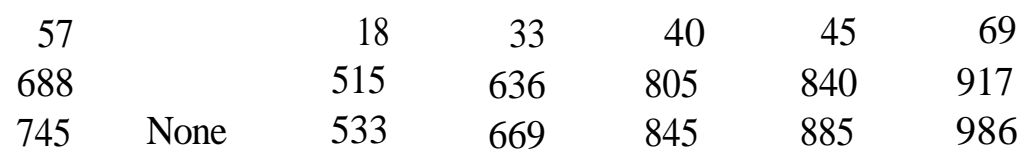

Probability of

Detection:

0.0765

0.0493

0.0473

0.0508

0.0700

$\chi^{2} \mathrm{p}$-value $=0.0111, \quad \bar{p}=0.0515$ 
O bservation Site: Snake River Trap J uvenile (SNJ)

Migration Year: $\quad 89 \quad 90 \quad 91 \quad 92$

\begin{tabular}{|c|c|c|c|c|c|c|}
\hline Detected: & 0 & & 0 & 0 & 0 & 0 \\
\hline Not detected: & 745 & & 533 & 669 & 845 & 0 \\
\hline Released: & 745 & None & 533 & 669 & 845 & 885 \\
\hline
\end{tabular}

Probability of

Detection:

0

$0 \quad 0$

0

0

0

$\chi^{2} \mathrm{p}$ value $=\mathrm{NA}, \bar{p}=0.00$

\section{Release Site: Salmon River South Fork (SALRSF) (summer chinook)}

O bservation Site: Lower Granite J uvenile (GR J)

$\begin{array}{llllllll}\text { Migration Year: } & 89 & 90 & 91 & 92 & 93 & 94 & 95\end{array}$

$\begin{array}{lrrrrrr}\text { Detected: } & 84 & 98 & 81 & 173 & 446 & 78\end{array}$

$\begin{array}{lllllll}\text { Not detected: } & 2142 & 894 & 950 & 1545 & 5505 & 1496\end{array}$

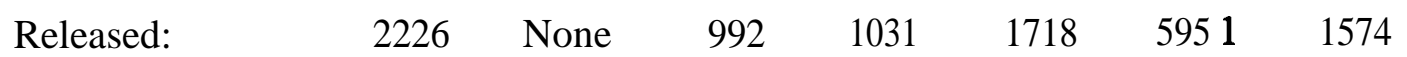

Probability of

$\begin{array}{lllllll}\text { Detection: } & 0.0377 & 0.0988 & 0.0786 & 0.1007 & 0.0749 & 0.0496\end{array}$

$\chi^{2} \mathrm{p}$ value $<0.0001, \bar{p}=0.0781$

O bservation Site: Snake R iver Trap J uvenile (SN J)

$\begin{array}{llllllll}\text { Migration Year: } & 89 & 90 & 91 & 92 & 93 & 94 & 95\end{array}$

\begin{tabular}{|c|c|c|c|c|c|c|c|}
\hline Detected: & 2 & & 0 & 1 & 2 & 5 & 1 \\
\hline Not detected: & 2224 & & 992 & 1030 & 1716 & 5946 & 1573 \\
\hline Released: & 2226 & None & 992 & 1031 & 1718 & 5951 & 1574 \\
\hline
\end{tabular}

Probability of

$\begin{array}{lllllll}\text { Detection: } & 0.0009 & 0 & 0.0010 & 0.0012 & 0.0008 & 0.0006\end{array}$

$\chi^{2} \mathrm{p}$ value $=0.8974, p_{p}=0.0008$ 


\section{Release Site: Secesh_River (SECESR) (summer_chinook)}

O bservation Site: Lower Granite J uvenile

$\begin{array}{lrrrrrrr}\text { Migration Year: } & 89 & 90 & 91 & 92 & 93 & 94 & 95 \\ & & & & & & & \\ \text { Detected: } & 190 & 157 & 71 & 40 & 30 & 33 & 90 \\ \text { Not detected: } & 1750 & 2019 & 947 & 973 & 297 & 389 & 1461 \\ \text { Released: } & 1940 & 2176 & 1018 & 1013 & 327 & 422 & 1551\end{array}$

Probability of

$\begin{array}{llllllll}\text { Detection: } & 0.0979 & 0.0722 & 0.0697 & 0.0395 & 0.0917 & 0.0782 & 0.0580\end{array}$

$\chi^{2} \mathrm{p}$ value $<0.0001, \bar{p}=0.0749$

O bservation Site:Snake R iver Trap J uvenile (SN J)

$\begin{array}{llllllll}\text { Migration Year: } & 89 & 90 & 91 & 92 & 93 & 94 & 95\end{array}$

$\begin{array}{lrrrrrrr}\text { Detected: } & 3 & 0 & 0 & 0 & 0 & 0 & 3 \\ \text { Not detected: } & 1937 & 2176 & 1018 & 1013 & 327 & 422 & 1548\end{array}$

$\begin{array}{llllllll}\text { Released: } & 1940 & 2176 & 1018 & 1013 & 327 & 422 & 1551\end{array}$

Probability of

$\begin{array}{llllllll}\text { Detection: } & 0.0015 & 0 & 0 & 0 & 0 & 0 & 0.0019\end{array}$

$\chi^{2} \mathbf{p}$ value $=0.1756, p_{p}=0.0004$

\section{Release Site: Vallev Creek (VALEYC)_(spring chinook)-}

O bservation Site: Lower Granite J uvenile (GR J)

$\begin{array}{lrrrrrrr}\text { Migration Year: } & 89 & 90 & 91 & 92 & 93 & 94 & 95 \\ & & & & & & & \\ \text { Detected: } & 74 & 76 & 41 & 34 & 33 & 46 & 50 \\ \text { Not detected: } & 1868 & 2436 & 990 & 935 & 995 & 804 & 1502 \\ \text { Released: } & 1942 & 2512 & 1031 & 969 & 1028 & 850 & 1552\end{array}$

Probability of

$\begin{array}{llllllll}\text { Detection: } & 0.0381 & 0.0303 & 0.0398 & 0.0351 & 0.0321 & 0.0541 & 0.0322\end{array}$

$\chi^{2} \mathrm{p}$ value $=0.0446, \bar{p}=0.0383$ 
O bservation Site: Snake R iver T rap J uvenile (SNJ)

Migration Year:

89

90

91

92

$\begin{array}{lll}93 & 94 & 95\end{array}$

Detected:

0

2

0

0

$\begin{array}{rrr}0 & 1 & 0 \\ 1028 & 849 & 1552 \\ 1028 & 850 & 1552\end{array}$

Released:

1942

2512

1013

969

1028

1552

Probability of

Detection:

$\begin{array}{ll}0 & 0.0008\end{array}$

0

0

0.0012

0

$\chi^{2} \mathrm{p}$ value $=0.4568, p_{p}=0.0004$

\section{O ther R elease Sites I nvestigated}

\section{Release Site: Alturas Lake Creek (ALTLLC) (spring chinook)}

O bservation Site: L ower G ranite J uvenile (G R J )

Migration Year:

89

90

91

92

93

94

95

Detected:

Not detected:

$\begin{array}{rrrrrrr} & 4 & 11 & 2 & 18 & & 8 \\ & 1039 & 426 & 155 & 367 & & 412 \\ \text { None } & 1043 & 437 & 157 & 385 & \text { None } & 420\end{array}$

Released:

Probability of

Detection:

$$
\begin{array}{llll}
0.0038 & 0.0252 & 0.0127 & \mathbf{0 . 0 4 6 8}
\end{array}
$$

$\chi^{2} \mathrm{p}$ value $<0.0001, \bar{p}=0.0221$

O bservation Site: Snake R iver Trap J uvenile (SN J)

Migration Year:

89

$90 \quad 91$

92

$93 \quad 94 \quad 95$

Detected:

Not detected:

Released:

$\begin{array}{rrrrrrr} & 0 & 0 & 2 & 0 & & 0 \\ \text { None } & 1043 & 437 & 155 & 385 & & 420 \\ & 1043 & 437 & 157 & 385 & \text { None } & 420\end{array}$

Probability of

Detection:

0

$\begin{array}{ll}0 & 0.0127\end{array}$

0

0

$\chi^{2} \mathrm{p}$ value $<0.0001, \bar{p}=0.0032$ 


\section{Release Site: CaDe Horn Creek_(CAPEHC)_(spring_chinook)}

O bservation Site: L ower G ranite J uvenile (G R J )

Migration Year:

89

90

91

92

93

$94 \quad 95$

Detected:

$25 \quad 19$

$19 \quad 22$

$\begin{array}{ll}0 & 84\end{array}$

Not detected:

$139 \quad 190$

184

$460 \quad 1361$

Released

None None 164

209

206

$460 \quad 1445$

Probability of

Detection:

$\begin{array}{lll}0.1524 & 0.0909 & 0.1068\end{array}$

$\begin{array}{ll}0 & 0.0581\end{array}$

$\mathrm{x} 2 \mathrm{p}$ value $<0.0001$, fi $=0.0875$

O bservation Site: Snake R iver T rap J uvenile (SN J)

Migration Year:

89

90

$91 \quad 92$

93

94

95

Detected:

Not detected:

Released:

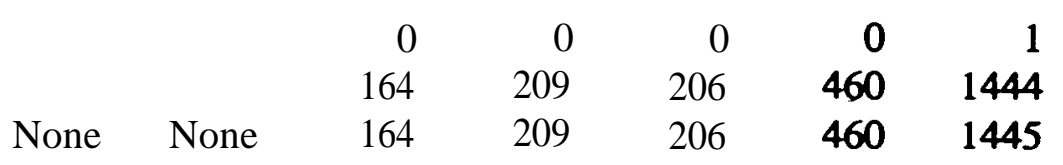

Probability of

Detection:

0

$\begin{array}{llll}0 & 0 & 0 & 0.0007\end{array}$

$\chi^{2} \mathrm{p}$ value $=\mathrm{NA}, \bar{p}=0.00$

\section{Release Site: Chamberlain Creek (CHAMBC) (spring chinook1}

O bservation Site: Lower Granite J uvenile (GR J )

Migration Year:

89

$90 \quad 91$

92

93

$94 \quad 95$

Detected:

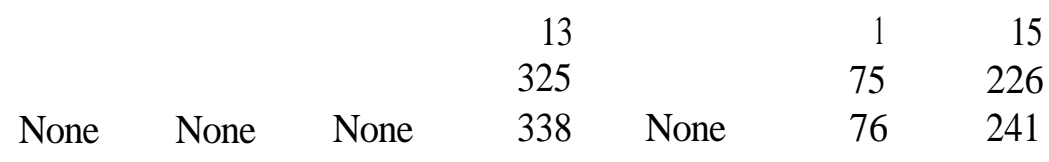

Probability of

Detection:

0.0385

$0.0132 \quad 0.0622$

$\chi^{2} \mathrm{p}$ value $=0.4523, p_{p}=0.0258$ 
O bservation Site: Snake R iver Trap J uvenile (SNJ )
Migration Year:
89
90
91
92
$93 \quad 94$
95
Detected:
Not detected:
Released:
None None $\quad 338$

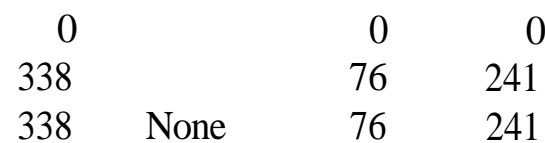
Probability of
Detection:
0
$0 \quad 0$
$\chi^{2} \mathrm{p}$ value $=\mathrm{NA}, \bar{p}=0.00$

Release Site: Chamberlain Creek. West Fork (CHAMWF) (spring chinook)

O bservation Site: Lower Granite J uvenile (G R J)

Migration Year:

$89 \quad 90 \quad 91 \quad 92$

Detected:

Not detected:

Released:

\begin{tabular}{|c|c|}
\hline & \\
\hline & \\
\hline one & None \\
\hline
\end{tabular}

Probability of

Detection:

$$
\begin{array}{llll}
0.0451 & 0.0980 & 0.0640 & 0.0491
\end{array}
$$

$\chi^{2} \mathrm{p}$ value $=0.0003, \bar{p}=0.0690$

O bservation Site: Snake River J uvenile (SNJ)

$\begin{array}{llllllll}\text { Migration Year: } & 89 & 90 & 91 & 92 & 93 & 94 & 95\end{array}$

Detected:

Not detected:

Released:

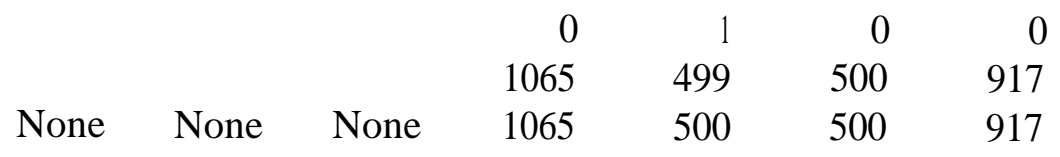

Probability of

Detection:

$\begin{array}{llll}0 & 0.0020 & 0 & 0\end{array}$

$\chi^{2} \mathrm{p}$ value $=0.2089, \quad p_{p}=0.0007$ 


\section{Release Site: Fourth of Julv Creek (4.JULYC) (spring chinook)}

\section{O bservation Site: Lower Granite J uvenile (GR J)}

Migration Year:

89

$90 \quad 91$

92

93

94

95

Detected:

Not detected:

264

Released:

None None None None

273

None None

Probability of

Detection:

one years data only, so no average, $\mathrm{p}=0.0330$

\section{O bservation Site: Snake River Trap J uvenile (SN J)}

Migration Year:

89

90

91

92

93

94

95

Detected:

Not detected:

Released:

None None None None

Probability of

Detection:

one years data only, so no average, $\mathrm{p}=0.00$

Release Site: Frenchman Creek (FRENCC) (sorinp chinook)

\section{O bservation Site: Lower Granite J uvenile (GR J)}

Migration Year:

89

90

91

92

$93 \quad 94$

95

Detected:

Not detected:

\begin{tabular}{|c|c|c|c|c|c|c|}
\hline & & 5 & 14 & 53 & 0 & 21 \\
\hline & & 191 & 561 & 508 & 387 & 574 \\
\hline one & None & 196 & 575 & 561 & 387 & 595 \\
\hline
\end{tabular}

Probability of

Detection:

$$
\begin{array}{lll}
0.0255 & 0.0243 & 0.0945
\end{array}
$$

$0 \quad 0.0353$

$\chi^{2} \mathrm{p}$ value $<0.0001, \bar{p}=0.0361$ 


\section{O bservation Site:Snake R iver Trap J uvenile (SN J)}

Migration Year:

89

90

91

92

$93 \quad 94 \quad 95$

Detected:

Not detected:

Released:

None None

$\begin{array}{rrrrr}0 & 0 & 1 & 0 & 0 \\ 196 & 575 & 560 & 387 & 595 \\ 196 & 575 & 561 & 387 & 595\end{array}$

Probability of

Detection:

0

$0 \quad 0.0018$

0

0

$\chi^{2} \mathrm{p}$ value $=0.5589, p_{p}=0.0005$

\section{Release Site: Herd Creek (HERDC) (spring chinook)}

\section{O bservation Site: Lower Granite J uvenile (GR J)}

Migration Year:

89

90

91

92

93

94

95

Detected:

Not detected:

Released:

\begin{tabular}{|c|c|}
\hline & \\
\hline & \\
\hline None & None \\
\hline
\end{tabular}

Probability of

Detection:

$\chi^{2} \mathrm{p}$ value $=0.3616, p_{p}=0.0580$

\section{Release Site: Huckleberrv Creek (HLCKLC) (spring chinook)}

\section{O bservation Site: Lower Granite J uvenile (GR J)}

Migration Year:

89

90

91

92

93

94

Detected:

$\begin{array}{rrrrrr} & & 6 & & & 15 \\ & & 170 & & & 249 \\ \text { None None None } \quad 176 & \text { None None } \quad 264\end{array}$

Probability of

Detection: 
O bservation Site: Snake R iver Trap J uvenile (SN J)

$\begin{array}{llllllll}\text { Migration Year: } & 89 & 90 & 91 & 92 & 93 & 94 & 95\end{array}$

Detected: $\quad 0 \quad 0$

Not detected: $\quad 176 \quad 264$

Released: None None None 176 None None 264

Probability of

Detection:

one years data only, so no average, $p=0.00$

Release Site: Lemhi Weir (LEMHIW) (soring chinook)

O bservation Site: L ower G ranite J uvenile (G R J )

$\begin{array}{llllllll}\text { Migration Year: } & 89 & 90 & 91 & 92 & 93 & 94 & 95\end{array}$

$\begin{array}{lllll}\text { Detected: } & \mathbf{8 2} & \mathbf{8 5} & 334\end{array}$

$\begin{array}{llll}\text { Not detected: } & \mathbf{5 5 3} & \mathbf{6 6 5} & 1452\end{array}$

$\begin{array}{lllllll}\text { Released: } & \text { None None None None } & \mathbf{6 3 5} & \mathbf{7 5 0} & 1786\end{array}$

Probability of

Detection:
$0.1291 \quad 0.1133 \quad 0.1870$

$\chi^{2} \mathrm{p}$ value $=0.4139, p_{p}=0.1371$

Observation Site:Snake River Juvenile (SNJ)

$\begin{array}{llllllll}\text { Migration Year: } & 89 & 90 & 91 & 92 & \mathbf{9 3} & \mathbf{9 4} & 95\end{array}$

Detected:

Not detected:

Released:

None None None None

$\begin{array}{rrr}\mathbf{0} & 1 & 1 \\ \mathbf{6 3 5} & \mathbf{7 4 9} & 1785 \\ \mathbf{6 3 5} & \mathbf{7 5 0} & 1786\end{array}$

Probability of

Detection:

$\begin{array}{lll}0 & 0.0013 & 0.0006\end{array}$

$\chi^{2} \mathrm{p}$ value $=0.9336, p_{p}=0.0007$ 


\section{Release Site: Looking Glass Creek (LOOKGC) (spring chinook)}

O bservation Site: Lower G ranite J uvenile (G R J )

$\begin{array}{llllllll}\text { Migration Year: } & 89 & 90 & 91 & 92 & 93 & 94 & 95\end{array}$

Detected: $\quad 241 \quad 285$

Not detected: $\quad 1762 \quad 3329$

Released: None None None None None $2003 \quad 3614$

Probability of

Detection:

$0.1203 \quad 0.0789$

one years data only, so no average, $\mathrm{p}=0.1203$

O bservation Site: Snake River Trap J uvenile (SNJ)

$\begin{array}{llllllll}\text { Migration Year: } & 89 & 90 & 91 & 92 & 93 & 94 & 95\end{array}$

Detected:

Not detected:

Released:

None None None None None $2003 \quad 3614$

Probability of

Detection:

$0.0005 \quad 0.0006$

one years data only, so no average, $p=0.0005$

\section{Release Site: Pole Creek (POLEC) (spring chinook)}

O bservation Site: Lower G ranite J uvenile (G R J)

$\begin{array}{llllllll}\text { Migration Year: } & 89 & 90 & 91 & 92 & 93 & 94 & 95\end{array}$

Detected: $\quad 8$

Not detected:

188

Released: None None 196 None None None None

Probability of

Detection:

0.0408

one year's data only, so no average, $\mathrm{p}=0.0408$ 
O bservation Site: Snake R iver Trap J uvenile (SN J)

Migration Year:

$\begin{array}{lllllll}89 & 90 & 91 & 92 & 93 & 94 & 95\end{array}$

Detected: $\quad 0$

Not detected: $\quad 196$

Released: None None 196 None None None None

Probability of

Detection:

one year's data only, so no average, $p=0.00$

\section{Release Site: Salmon River North Fork (SALRNF) (Spring chinook)}

O bservation Site: Lower Granite J uvenile (GR J)

Migration Year:

89

$90 \quad 91$

92

93

94

95

D etected:

27
486

Not detected:

Released:

None None None None

$486 \quad 214$

484

$513 \quad 233 \quad 520$

Probability of

Detection:

$$
\begin{array}{lll}
0.0526 & 0.0815 & 0.0692
\end{array}
$$

$\chi^{2} \mathrm{p}$ value $=0.1747, p_{p}=0.0617$

O bservation Site: Snake River Trap J uvenile (SN J )

Migration Year:

89

$90 \quad 91$

92

$93 \quad 94 \quad 95$

Detected:

Not detected:

Released:

None None None None

$\begin{array}{rrr}0 & 0 & 1 \\ 513 & 233 & 519 \\ 513 & 233 & 520\end{array}$

Probability of

Detection:

$\begin{array}{lll}\mathbf{0} & \mathbf{0} & 0.0019\end{array}$

$\chi^{2} \mathrm{p}$ value $=\mathrm{NA}, \bar{p}=0.0000$ 
Release Site: Smilev Creek (SMULC) (soring chinook)

O bservation Site: Lower G ranite J uvenile (GR J)

Migration Year:

89

90

91

92

93

$94 \quad 95$

Detected:

Not detected:

Released:

None

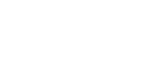

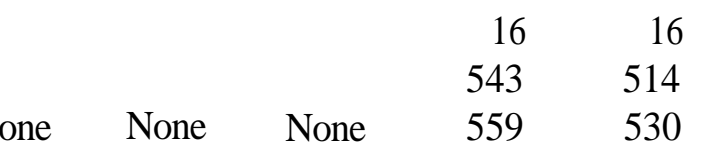

Probability of

Detection:

$$
0.0286 \quad 0.0302
$$

One year's data only, so no average, $\mathrm{p}=0.0286$

O bservation Site: Snake River Trap J uvenile (SN J)

Migration Year: $\quad 89 \quad 90 \quad 91 \quad 92$

$93 \quad 94 \quad 95$

Detected:

Not detected:

Released:

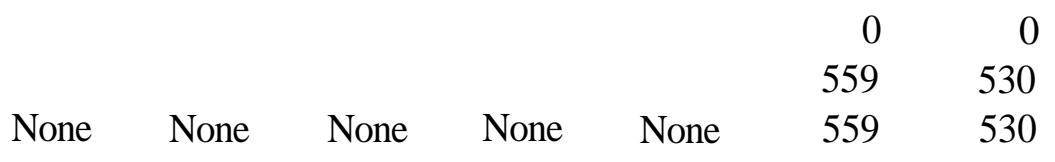

Probability of

Detection:

$0 \quad 0$

One year's data only, so no average, $p=0.00$

\section{Release Site:Snake River (SNAKER) (spring chinook)}

\section{O bservation Site:L ower G ranite J uvenile (GR J)}

Migration Year:

$$
89
$$

$90 \quad 91$

92

93

Detected:

Not detected:

Released:

None None None

None

None

582 None

Probability of

Detection:

One year's data only, so no average, $\mathrm{p}=0.2835$ 


\section{Release Site:Sulfur Creek (SULFLC) (spring chinook)}

Observation Site:Lower Granite Juvenile (GRJ)

Migration Year:

89

90

91

92

93

94

95

Detected:

168

Not detected:

2348

Released:

None 2516

$24 \quad 28$

$186 \quad 686$

56

672

$210 \quad 714 \quad$ None 728

Probability of

Detection:

$$
0.0668
$$

$0.1143 \quad 0.0392$

0.0769

$\chi^{2} \mathrm{p}$ value $=0.0003, \bar{p}=0.0734$

Observation Site:Snake River Trap Juvenile (SN J)

$\begin{array}{llllllll}\text { Migration Year: } & 89 & 90 & 91 & 92 & 93 & 94 & 95\end{array}$

Detected: $\quad 0 \quad 0000$

$\begin{array}{lllll}\text { Not detected: } & 2516 & 210 & 714 & 728\end{array}$

$\begin{array}{lllllll}\text { Released: } & \text { None } & 2516 & \text { None } & 210 & 714 & \text { None }\end{array}$

Probability of

Detection:

0

0

0

0

$\chi^{2} \mathrm{p}$ value $=\mathrm{NA}, \bar{p}=0.00$

\section{Release Site: Wenaha River (WENR)_Spring_chinook)}

\section{Observation Site:Lower Granite Juvenile}

Migration Year:

$89 \quad 90 \quad 91$

92

$93 \quad 94$

95

Detected:

Not detected:

Released:

$\begin{array}{lllll} & & 173 & 191 & 238 \\ & & & & \\ \text { None None None None } & 196 & 212 & 259\end{array}$

Probability of

Detection:

$\begin{array}{lll}0.1173 & 0.0991 & 0.0811\end{array}$

$\chi^{2} \mathrm{p}$ value $=0.6633, p_{p}=0.1078$ 
O bservation Site:S nake R iver Trap J uvenile (SNJ)

$\begin{array}{lllll}\text { Migration Year: } & 89 & 90 & 91 & 92\end{array}$

Detected:

Not detected:

Released:

\begin{tabular}{|c|c|c|c|c|c|c|}
\hline & & & & & 0 & 0 \\
\hline & & & & 19 & 212 & 259 \\
\hline None & None & None & None & 19 & 212 & 259 \\
\hline
\end{tabular}

Probability of

Detection:

$\mathrm{x} 2 \mathrm{p}$ value $=0.9687, p_{p}=0.0025$

\section{Release Site:Wenaha River, South Fork (WENRSF) (soring chinook)}

O bservation Site:L ower G ranite J uvenile (G R J )

Migration Year:

89

90

91

92

93

94

95

Detected:

Not detected:

Released:

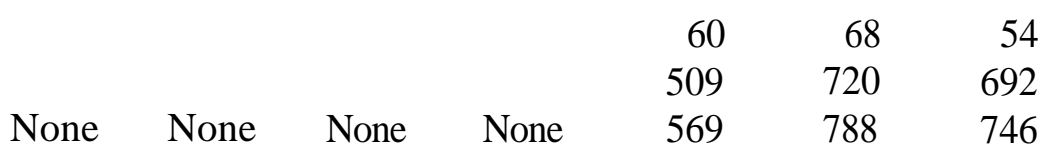

Probability of

Detection:

$\begin{array}{lll}0.1054 & 0.0863 & 0.0724\end{array}$

$\chi^{2} \mathrm{p}$ value $=0.2726, p_{p}=0.0943$

O bservation Site:Snake River Trap J uvenile (SNJ)

Migration Year:

89

$90 \quad 91$

92

93

94

95

Detected:

Not detected:

Released:

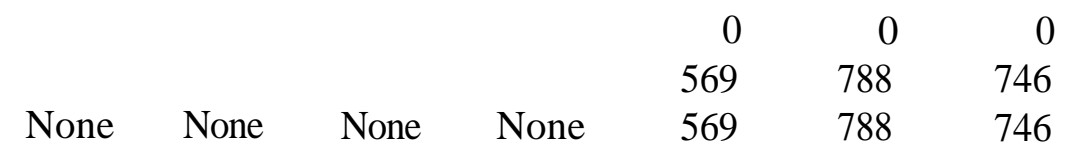

Probability of

Detection:

$\begin{array}{lll}0 & 0 & 0\end{array}$

$\chi^{2} \mathrm{p}$ value $=\mathrm{NA}, \bar{p}=0.00$ 


\section{Release Site:Sawtooth Trap (SAWTRP) (spring chinook)}

\section{Observation Site:Lower Granite Juvenile (GRJ)}

Migration Year:

89

90

91

92

93

$94 \quad 95$

Detected:

Not detected:

$\begin{array}{rrrrrr} & 74 & 0 & 48 & 4 & 106 \\ & 2629 & 403 & 1829 & 147 & 1237 \\ \text { None } \quad \text { None } \quad 2703 & 403 & 1877 & 151 & 1343\end{array}$

Probability of

Detection:

$$
0.0274
$$

$0 \quad 0.0256$

0.0265

0.0789

$\chi^{2} \mathrm{p}$ value $=0109, \bar{p}=0.0199$

\section{Observation Site:Snake River Trap Juvenile (SNJ)}

$\begin{array}{lrrrrrrr}\text { Migration Year: } & 89 & 90 & 91 & 92 & 93 & 94 & 95 \\ & & & & & & & \\ \text { Detected: } & & & 0 & 0 & 0 & \mathbf{0} & 1 \\ \text { Not detected: } & & & 2703 & 403 & 1877 & 151 & 1342 \\ \text { Released: } & \text { None } & \text { None } & 2703 & 403 & 1877 & 151 & 1343\end{array}$

Probability of

Detection:

0

$0 \quad 0$

$\begin{array}{ll}0 & 0.0007\end{array}$

Release Site:

$\chi^{2} \mathrm{p}$ value $=\mathrm{NA}, p_{p}=0.00$ 


\section{Appendix C}

\section{Graphical Capabilities of the $R$ ealT ime Program}




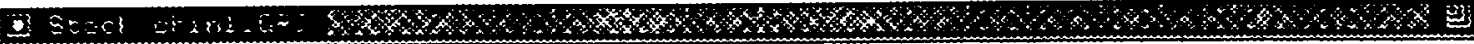

\section{Realtime PIT F orecaster}

\begin{tabular}{|c|c|c|c|c|c|c|}
\hline St rea m & Reach & Fish & ( Tags) & Hist & $t$ Yrs & (Vall) \\
\hline BEARKC & $17 C 60205$ & 35 & $(1455)$ & $5 Y$ & Years & $(1000)$ \\
\hline $\mathrm{BIGC}$ & 17060206 & 124 & $(1484)$ & $5 Y$ & Years & $(1308)$ \\
\hline Cathec & 17060104 & 107 & $(2061)$ & $4 Y$ & Years & $(100 x)$ \\
\hline CROTRP & +7060305 & 32 & $(1336)$ & $4 Y$ & Years & $(50 \%)$ \\
\hline ELKC & 17060205 & 46 & $(1512)$ & $4 Y$ & Years & C75W \\
\hline Cranda & 17060106 & 83 & (1898) & $3 Y$ & Years & $(500)$ \\
\hline IMNAHR & 17060102 & 27 & (999) & $6 Y$ & Years & $(100 \%)$ \\
\hline LOSTIR & 17050105 & 98 & $(1008)$ & 5 & Years & (IOab> \\
\hline HARSHC & 17060205 & 82 & (1575) & $5 Y$ & Years & $(100 \%)$ \\
\hline SALR & 17060209 & 3 & $(1217)$ & 5 & Years & $(1000)$ \\
\hline SALREF & 17060202 & 64 & $(986)$ & S & Years & $(828)$ \\
\hline SALRSF & 17060208 & 48 & $(1570)$ & $4 Y$ & Years & $(1008)$ \\
\hline SANTRP & 17060201 & 87 & (1343) & 4 & Years & $(50 x)$ \\
\hline SECESH & 17060208 & 73 & $(1557)$ & $6 Y$ & Years & $(100 \times)$ \\
\hline VALEYC & 17060201 & 11 & $(1552)$ & $6 Y$ & Years & $(100 x)$ \\
\hline
\end{tabular}

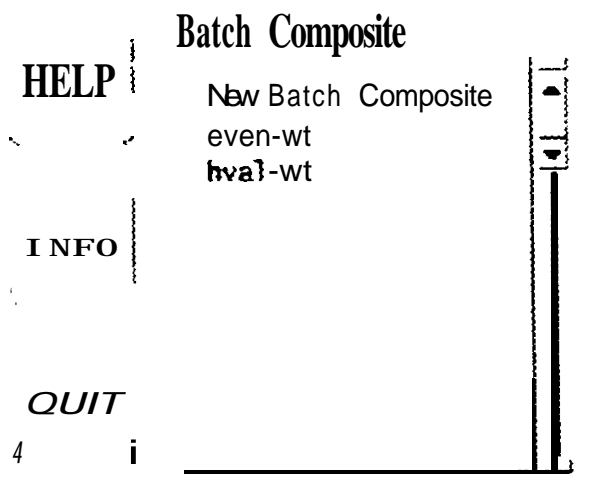

Batch Composite

1 (1552) 6 Years (100*)

Reach Sub-viewer

\begin{tabular}{|c|c|c|}
\hline Reach & Us able & St reams \\
\hline Shan & 0 of 3 & Streams \\
\hline Show 1 & of & Streams \\
\hline show 17060102 & 1 of 3 & Stream \\
\hline show 17060104 & 1 of 1 & Stream \\
\hline Show 17060105 & 1 al 1 & Stream \\
\hline show 17060106 & 1 of 5 & Stream \\
\hline show 17060301 & 2 of 14 & Streams \\
\hline Show 1702020 & $f$ of 7 & Streams \\
\hline Show 17360204 & af 6 & Streams \\
\hline
\end{tabular}

usabl e Strean Threshold: 01. 1100

The RedTime base window allows a user to view and analyze one or more streams or composite runs. A stream can be chosen by clicking the left mouse button on a selection in the stream selector. To choose a composite, click on a selection in the batch composite selector. When a choice is made, a stream or composite window pertaining to your choice will appear.

Clicking a second time on a selection will bring the corresponding stream or composite window to the front. Stream and composite windows can be deselected by clicking on the done button in the appropriate window.

The stream threshold slider and react1 subviewer allow a user to control which of the available streams in the database are listed in the stream selector.

The info and help buttons contain additional information about the RealTimeRealTime. 


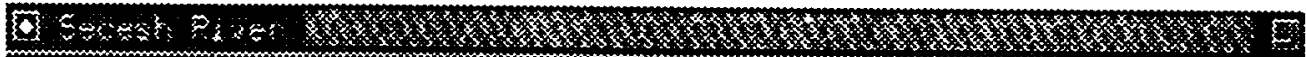

\begin{tabular}{|c|c|c|c|c|c|c|}
\hline \multicolumn{4}{|c|}{ Year Selector } & \multicolumn{3}{|c|}{ Historical Data Plots } \\
\hline HE LP & Year & Fish & Releases & \multirow{5}{*}{ 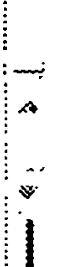 } & \multirow{5}{*}{$\begin{array}{l}\text { Raw Detections } \\
\text { Spi II-Adj ust ed Detecti ons } \\
\text { Number of Fish Passed } \\
\text { Pct of Fish Passed } \\
\text { Dail I Pct Detecti ons }\end{array}$} & \\
\hline$\because$ & 1989 & 190 & 1940 & & & \\
\hline \multirow{3}{*}{ DONE } & 1999 & 159 & 2176 & & & \\
\hline & 199 & 72 & 1018 & & & \\
\hline & 1992 & $\$ 1$ & 1043 & & & \\
\hline \multirow[t]{3}{*}{$\because$} & 1993 & 31 & 327 & & \multirow{2}{*}{\multicolumn{2}{|c|}{ Prediction Method Selector }} \\
\hline & 1934 & 39 & 422 & & & \\
\hline & Cur & $\begin{array}{l}\text { Year } \\
\text { fish }\end{array}$ & $\begin{array}{r}1995 \\
73 \\
1551\end{array}$ & & NEW LS Pattern Hatching & $\approx$ \\
\hline
\end{tabular}

After selecting the appropriate streams or composite to be analyzed, the stream or composite (depending on choice) window allows a user to view river data from historical and / or the current run for a selected tag site. We will use Secesh River as our example throughout. Select a prediction method to bring up a Results Frame and begin a prediction.

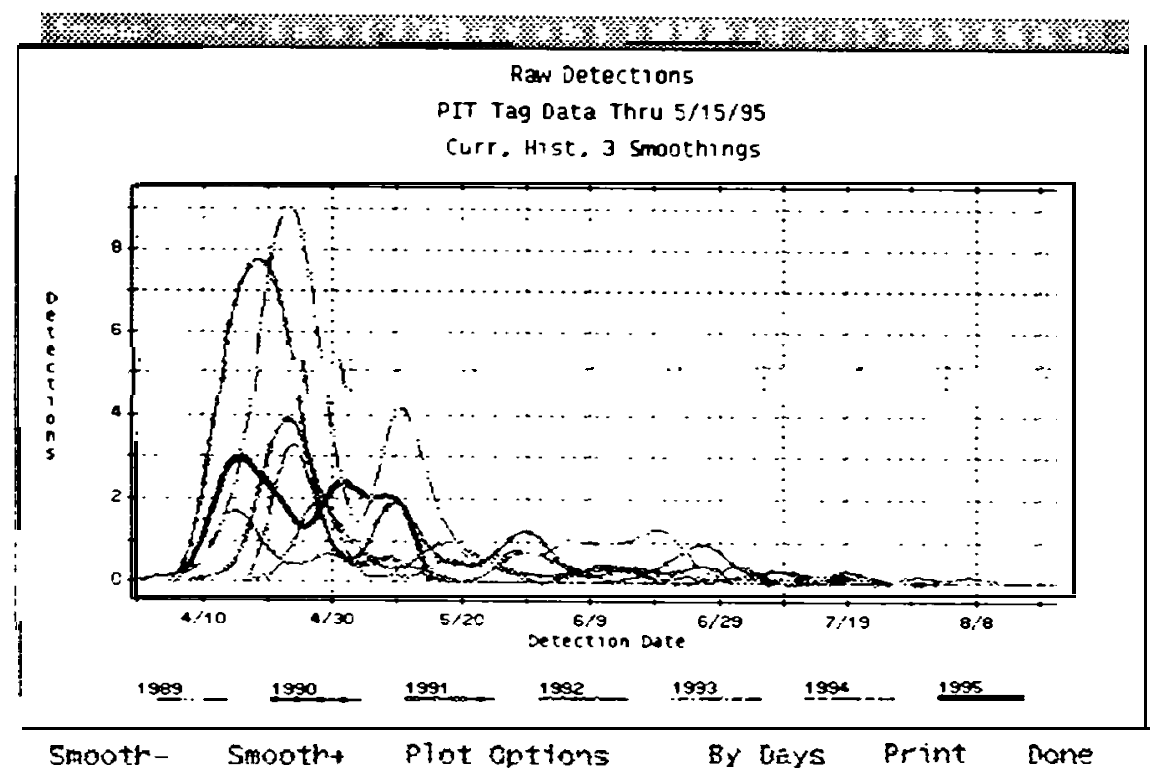

The raw detections window displays the number of raw detections for the selected tag site. Buttons below the draw window allow a user to specify the look of the graph. The graph data above is triple-smoothed for better visual clarity. 


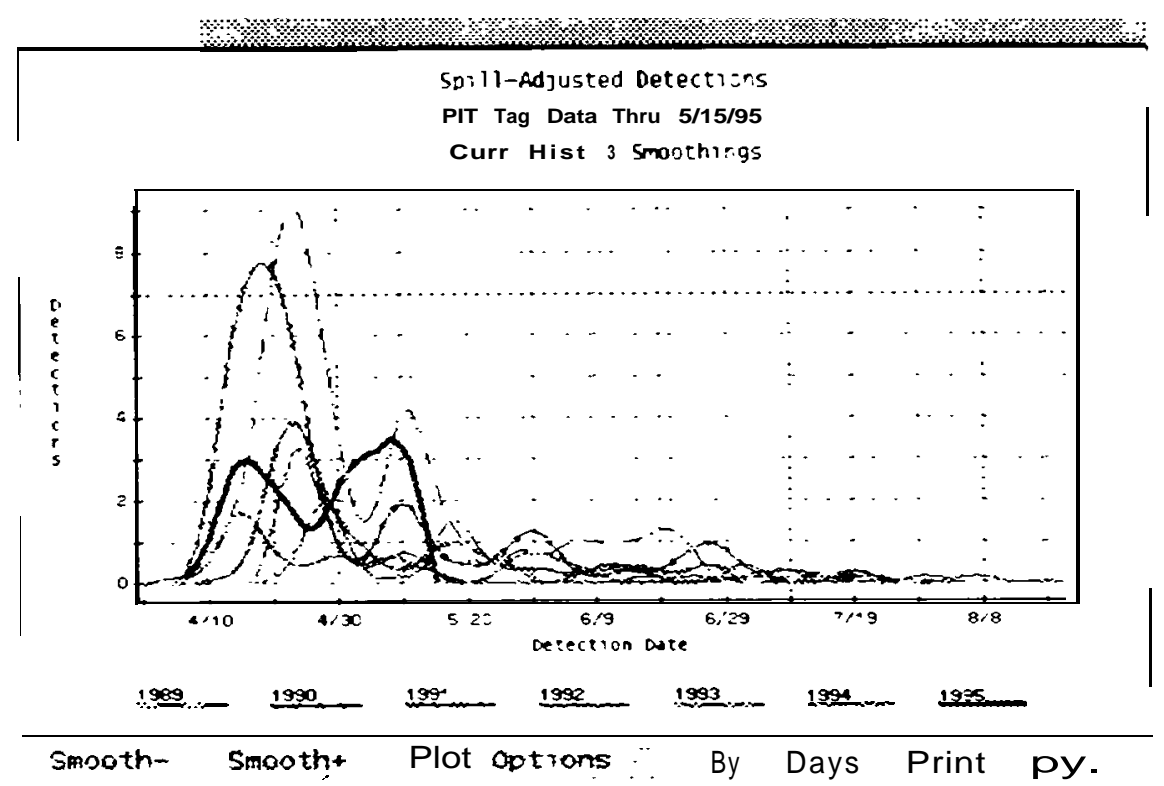

The spill-adjusted detections window displays fish counts adjusted by the spill percentage for the selected tag site.

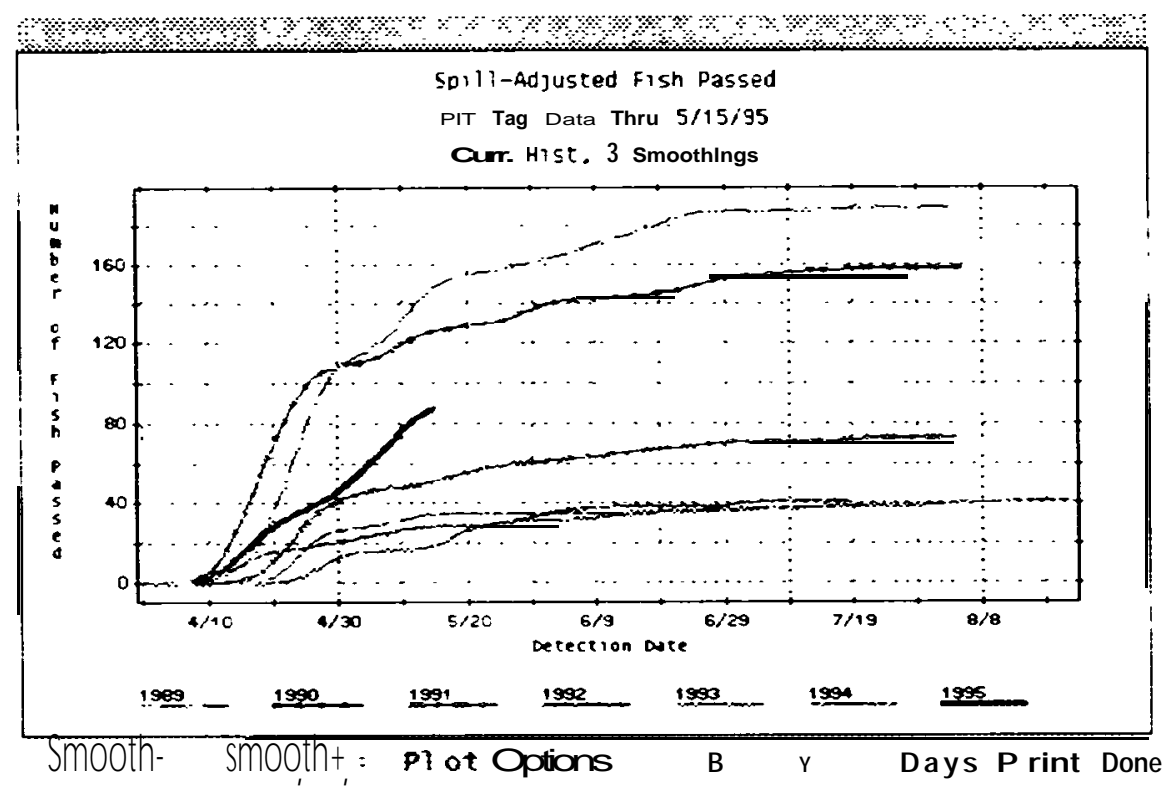

The cumulative detections window displays cumulative, spill-adjusted fish counts for the selected tag site. The prediction shown here is for May 15, 1995. 


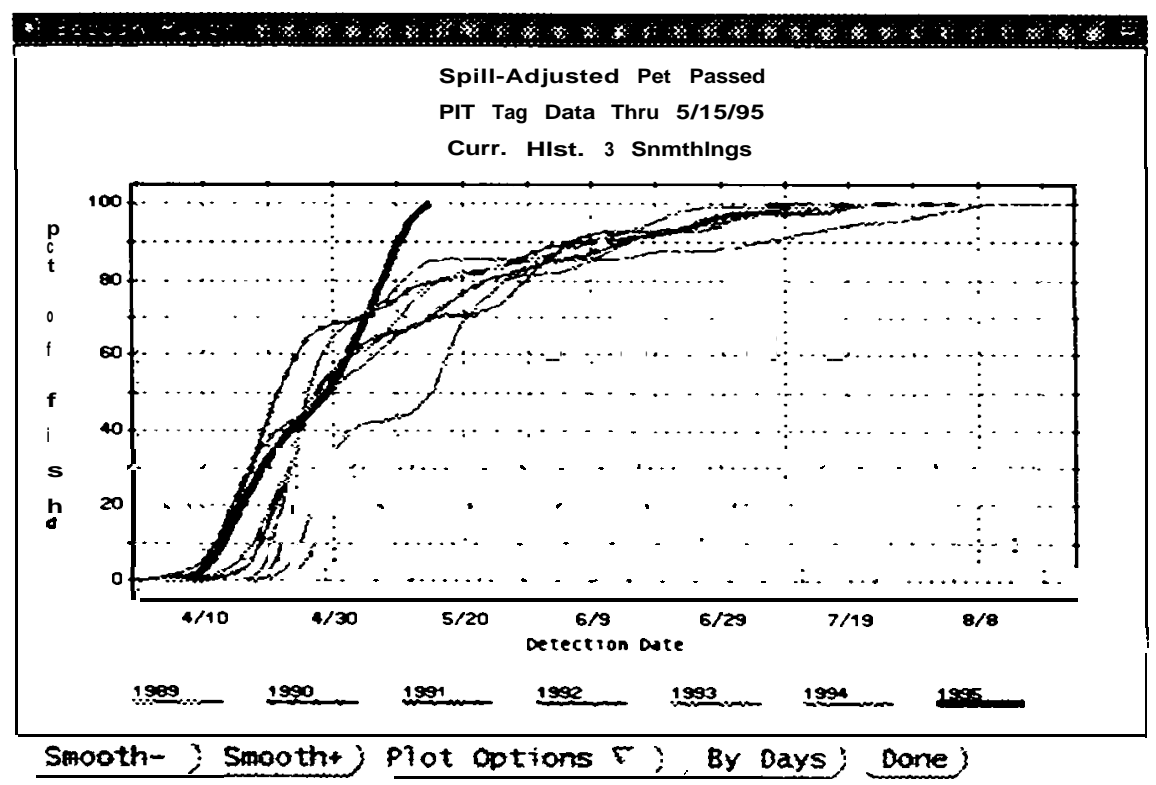

The percentage passed witldonp is a normalization of the cumulative detections window for the selected tag site for comparing historical run timings.

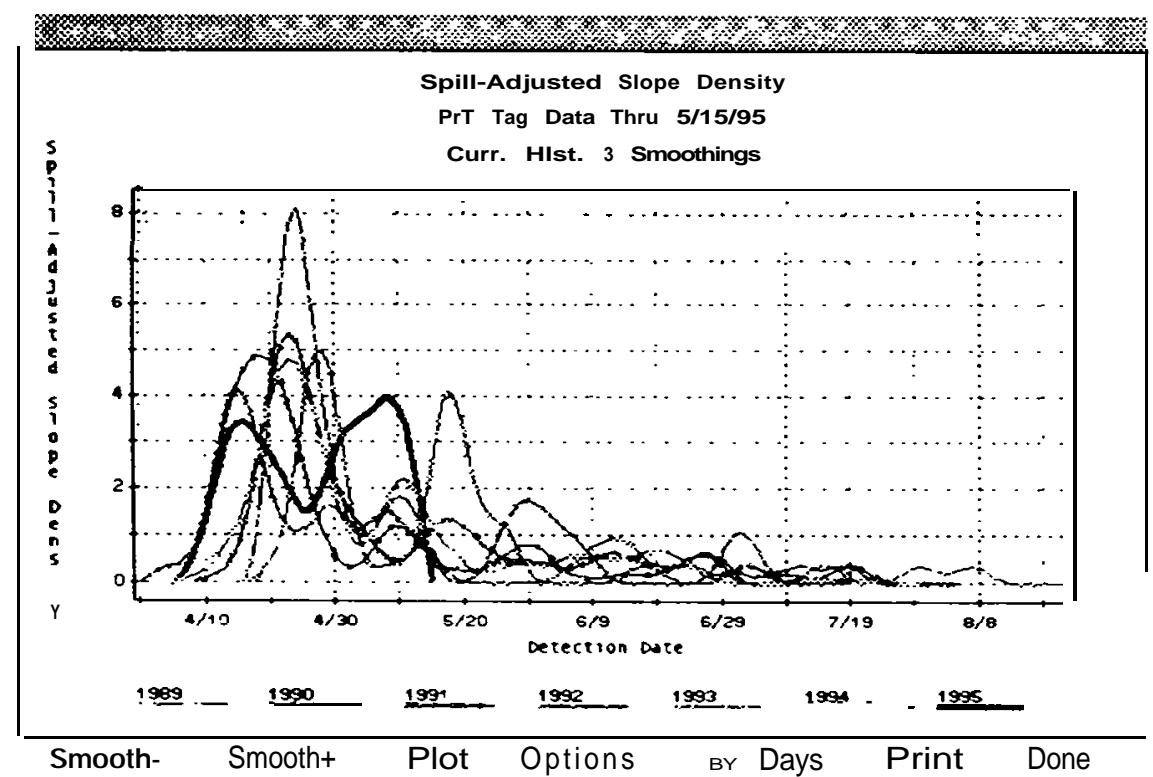

The slope density window displays the slope of the percentage passed window for the selected tag site for visual comparisons of historical run trends. Equivalently, it is a $100 \%$-area-normalization of the spill-adjusted detection window. 


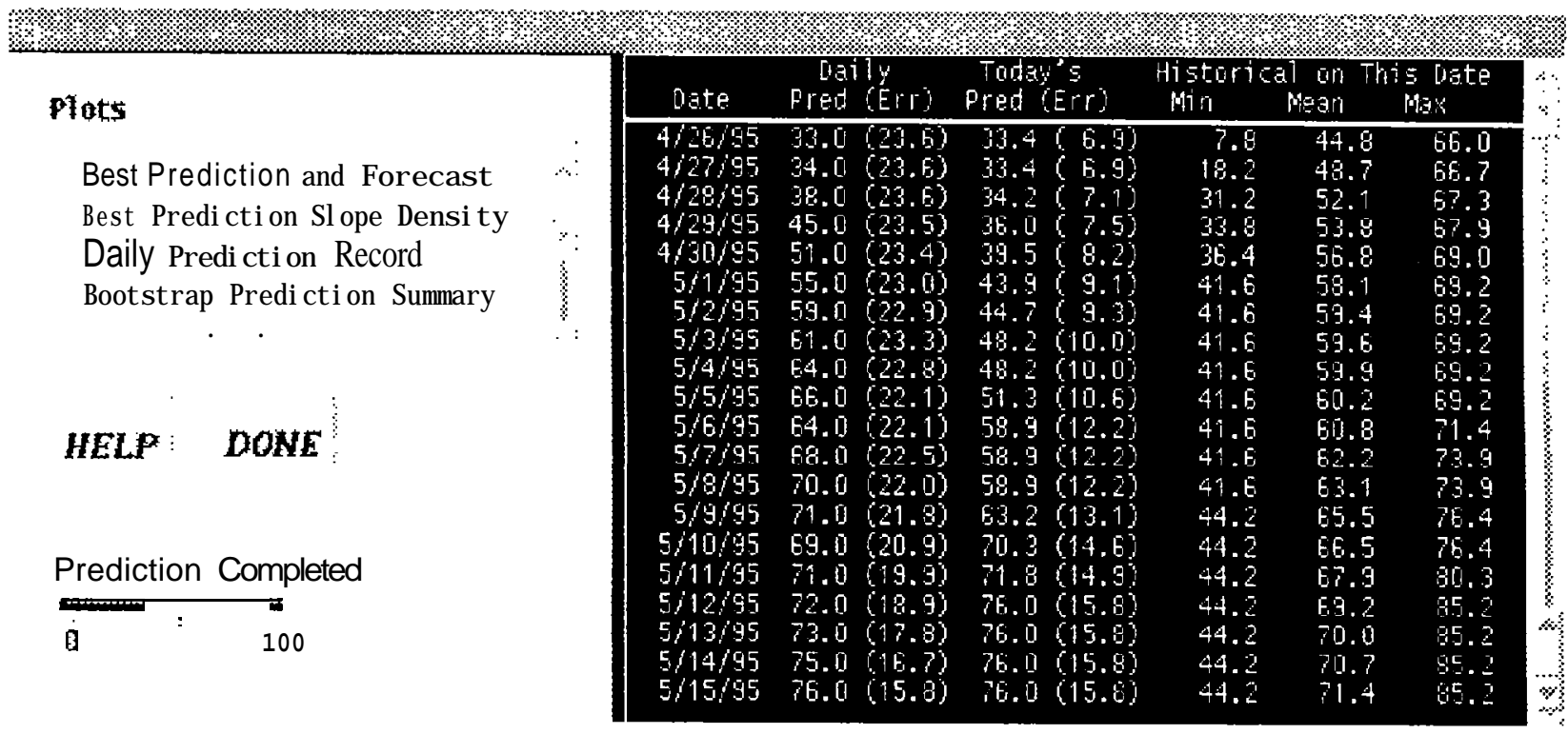

The results window displays a summary of daily predictions and historical data in the text window for the selected tag site. Daily predictions are a daily record of previous predictions, while today's predictions are the recalibrated daily predictions based on the present day's forecast. The plots selector allows a user to view one or more graphical results plots

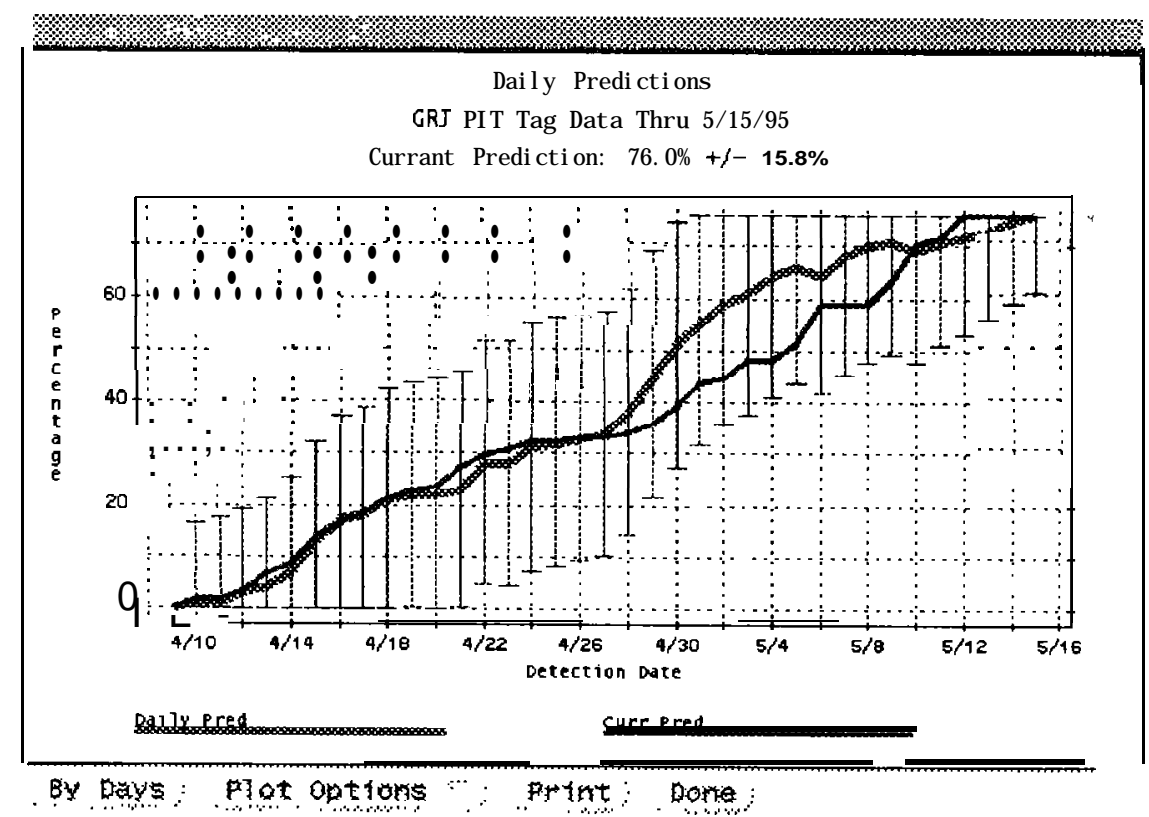

The daily predictions window displays the daily predictions made that were made on each day of the run for the selected tag site. The current prediction line shows the recalibrated prediction pattern up to most recent prediction of the current run. 


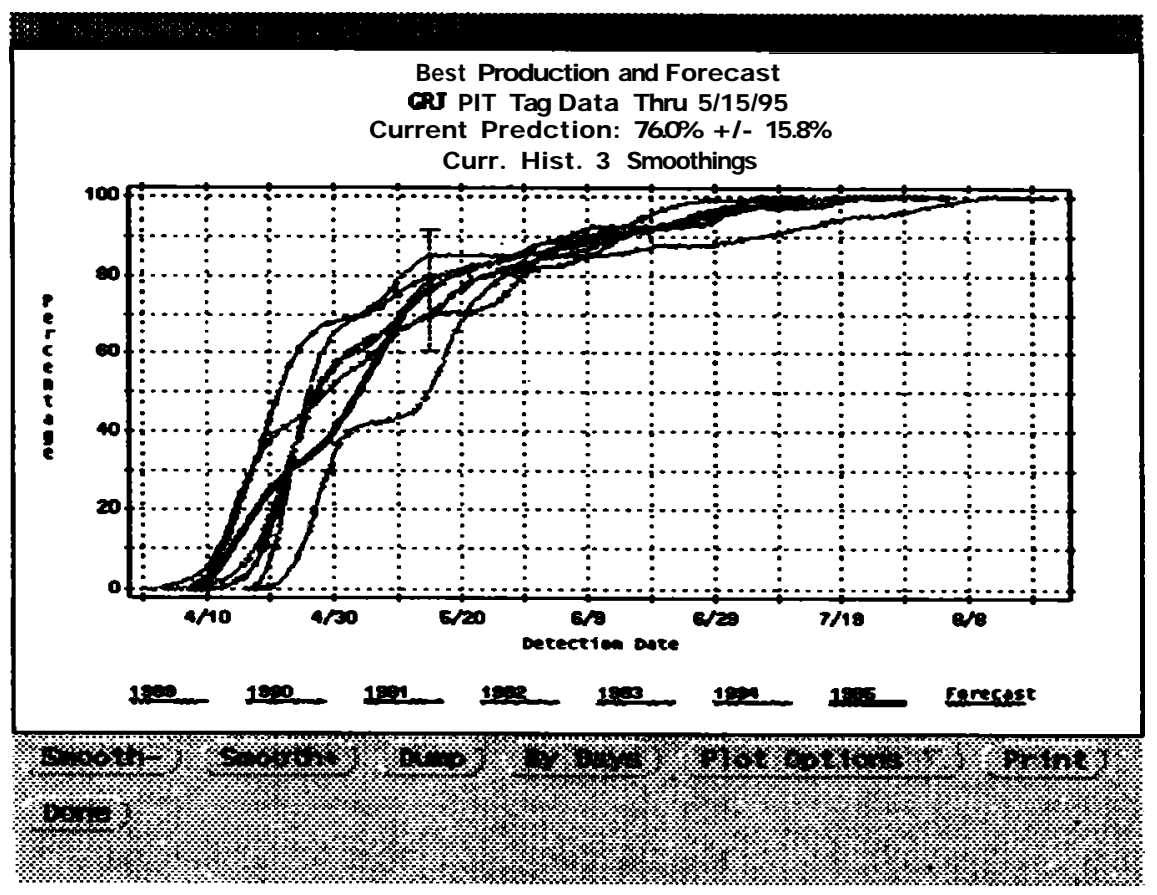

The best prediction and forecast window displays the current best prediction and forecast line with the historical runs in the prediction for the selected tag site. Thisgraphissimilartothe Percentage Passed graph, with the current run scaled to the current best prediction

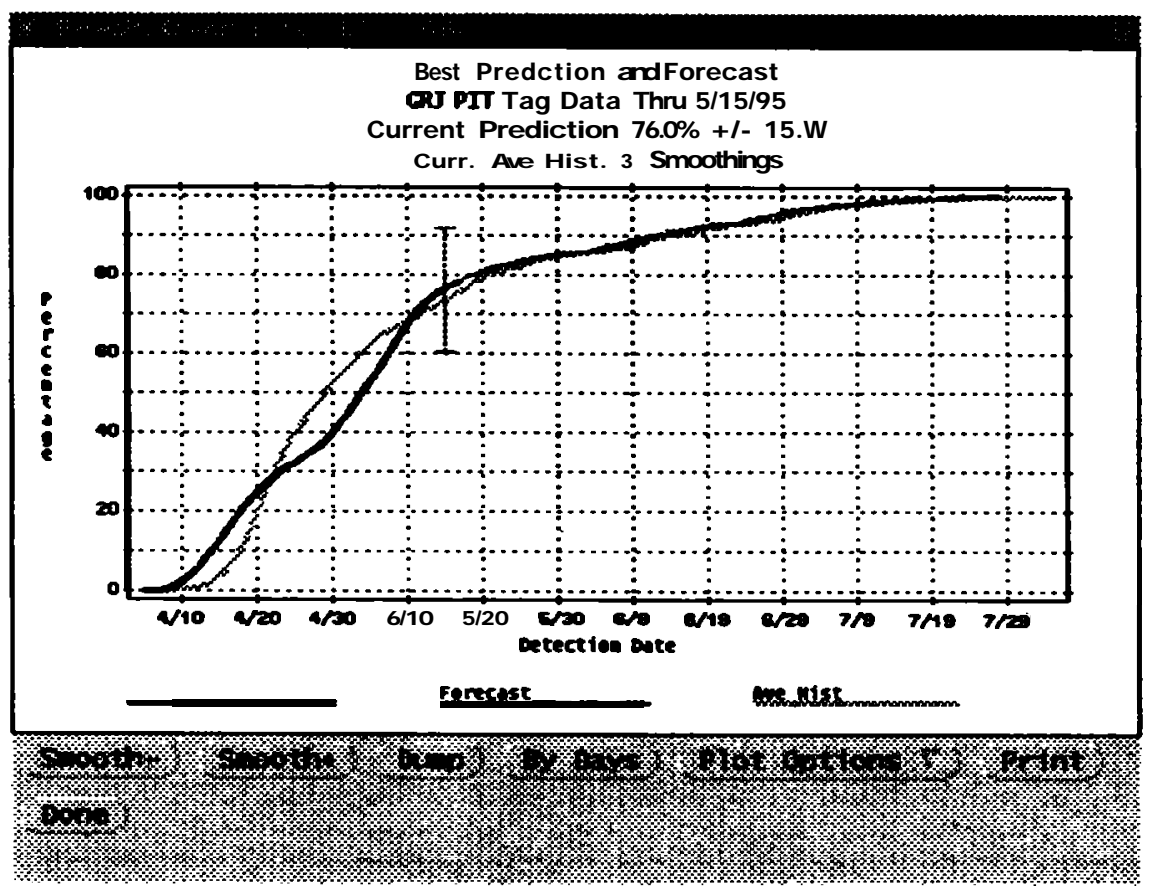

Another option in the prediction and forecast window displays the current best prediction line versus the average historical line, which represents the average historical date for each passage percentage. 


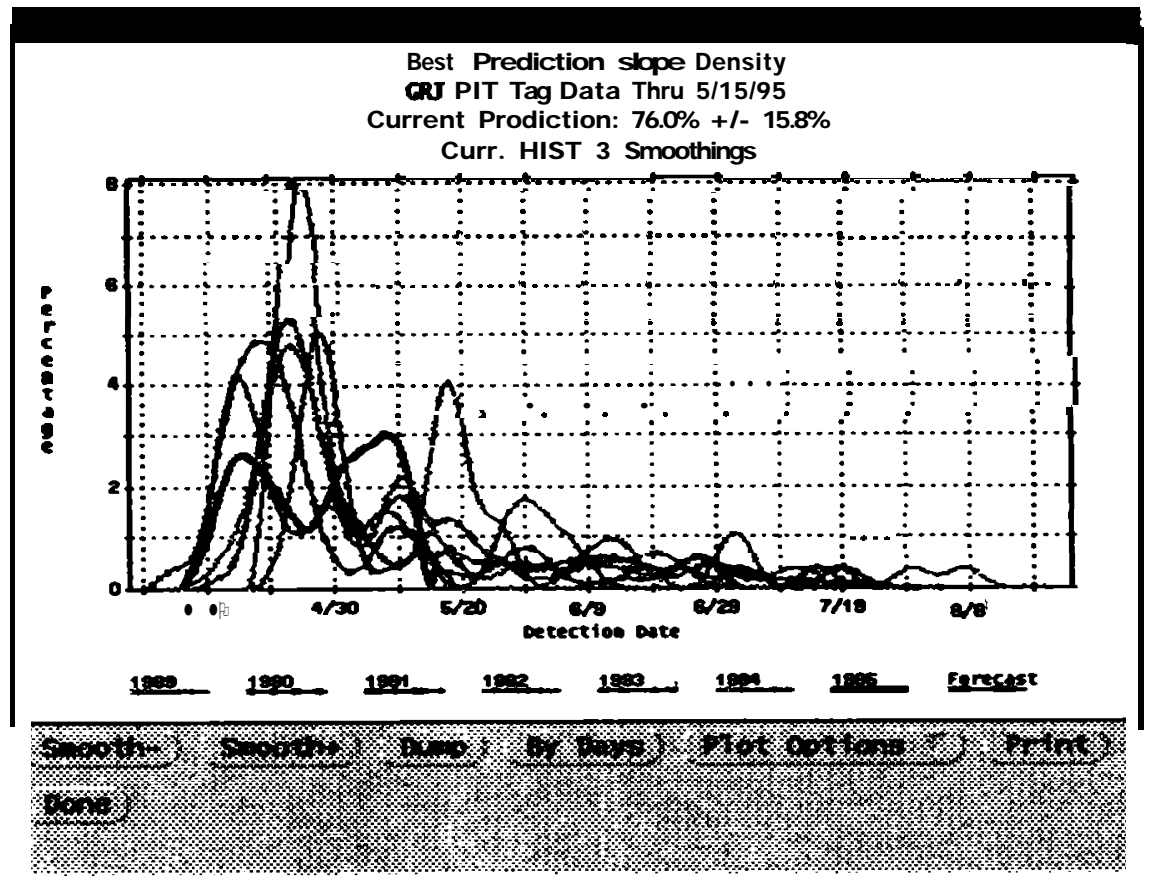

The prediction slope density window displays the slopes of the lines of the best prediction aad forecast window for the selected tag site. This is similar to the slape density graph, with the current run scaled to the current best prediction.

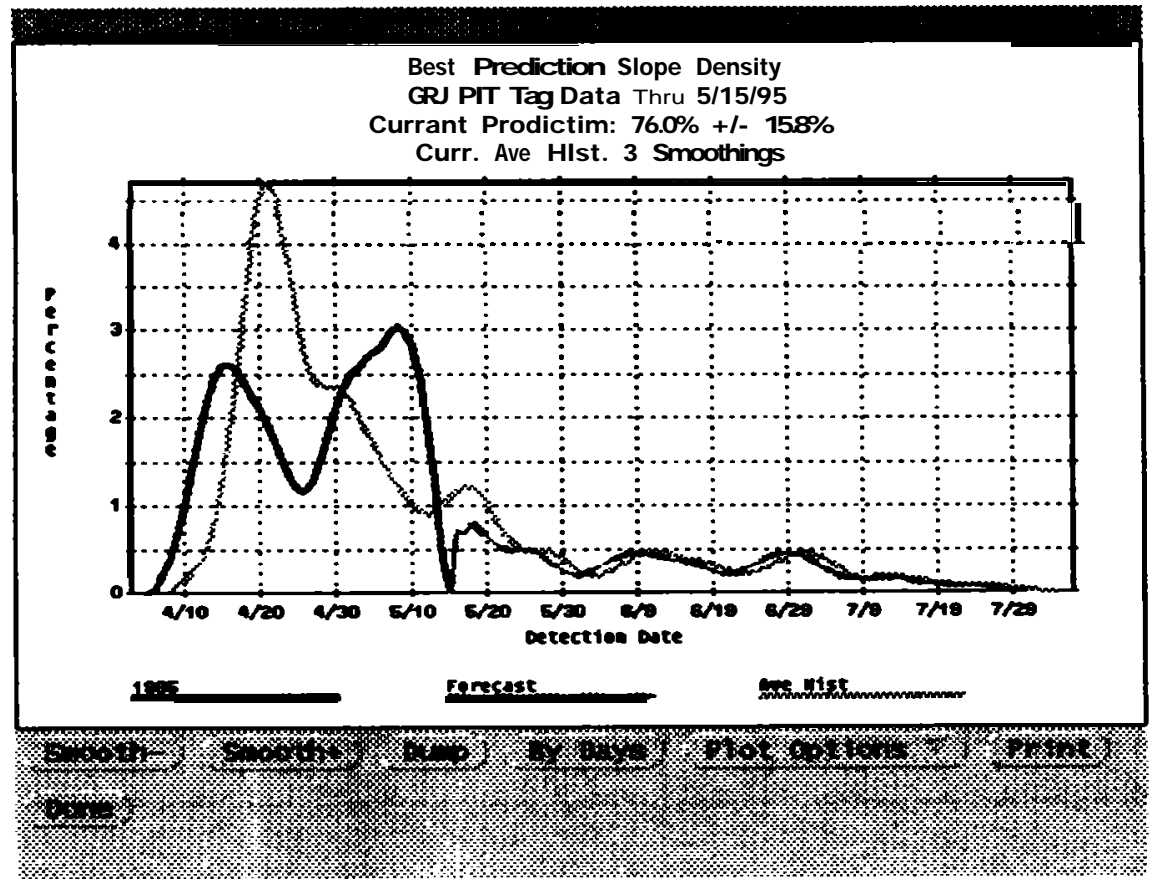

This window also has the option of comparing the current slope density line versus the avenge historical line. 


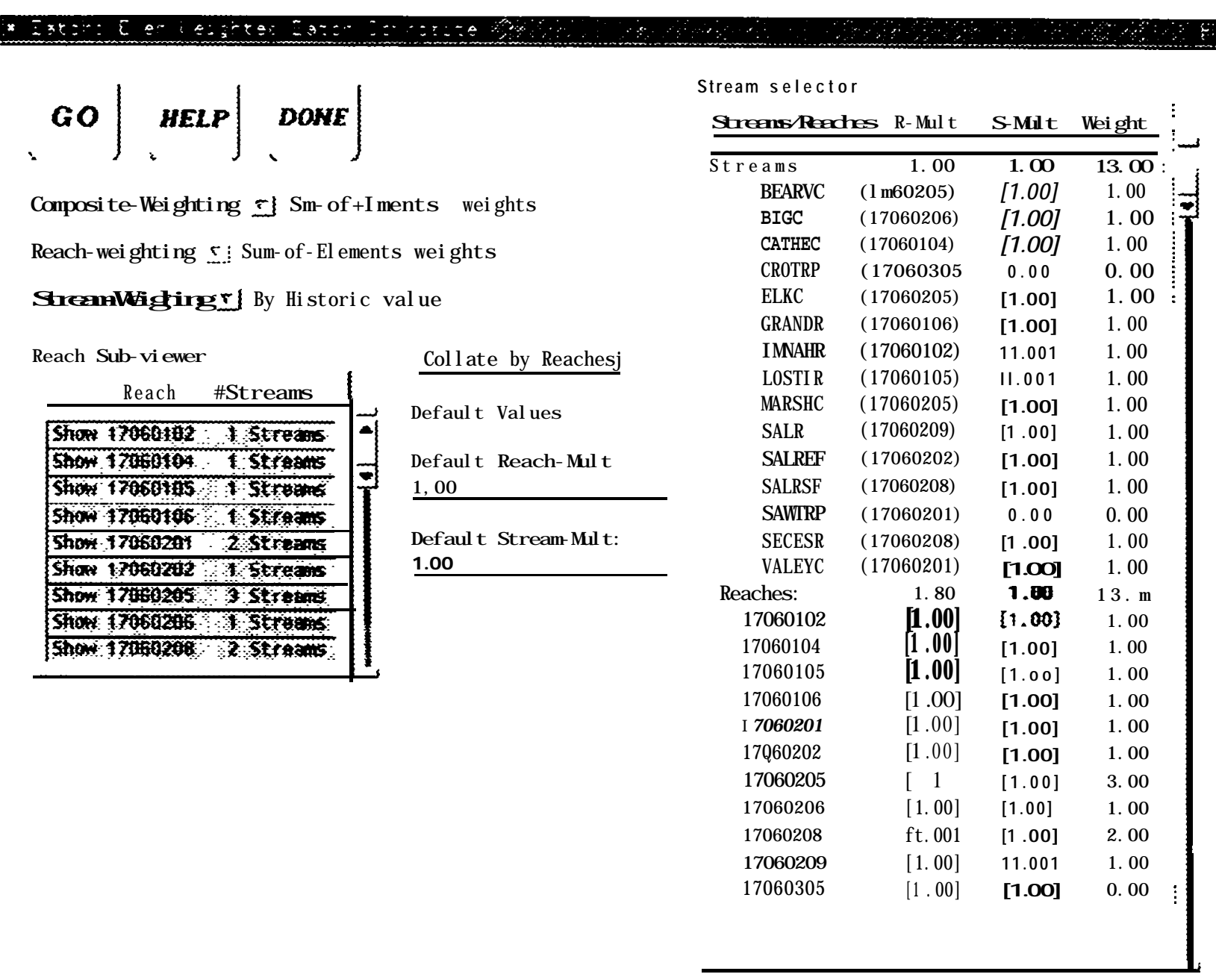

The composire window allows a user to modify a selected stream composite. Click on the Stream Selector to change the weighting of the selected stream. The weighting methods affect how these multipliers determine the stream's weight in the composite. The current weight of each stream is shown in the right-most column of the Stream Selector. The default weighting is 1 for each stream (evenly weighted). The sun-of-elements weighting method defines each stream within the composite as an element, then weights it according to its fraction of the total sum of weights. Normalized weights sets each reach's weight to 1 , then normalizes the weighting of each stream within that reach. Stream weighting by historical value gives each stream a weight calculated by the quality and consistancy of historical information available.

The reach sub-viewer and collation buttons allow the user to modify the display of the Stream Selector. These controls are included for user convenience.

To begin the composite run, click on the Go button 


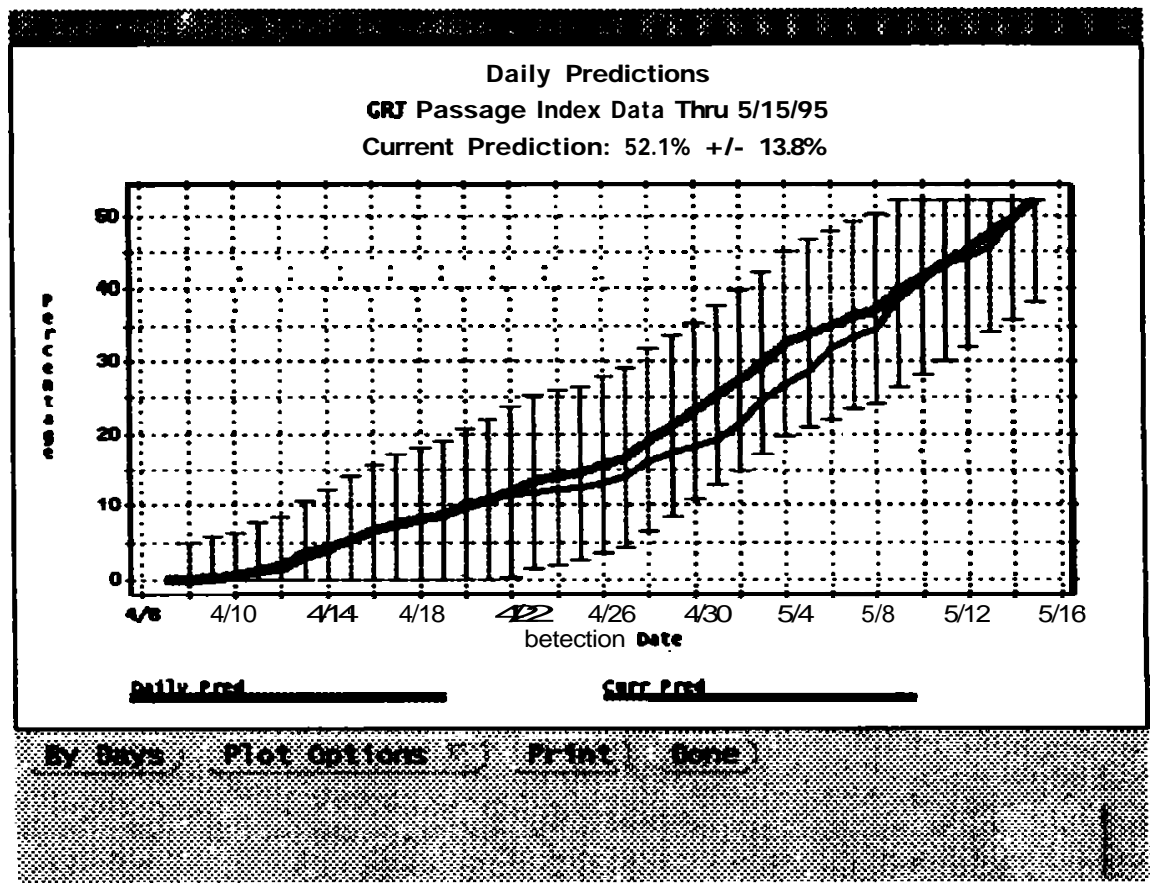

An example of the daily predictions window for the even-weighted composite run and the

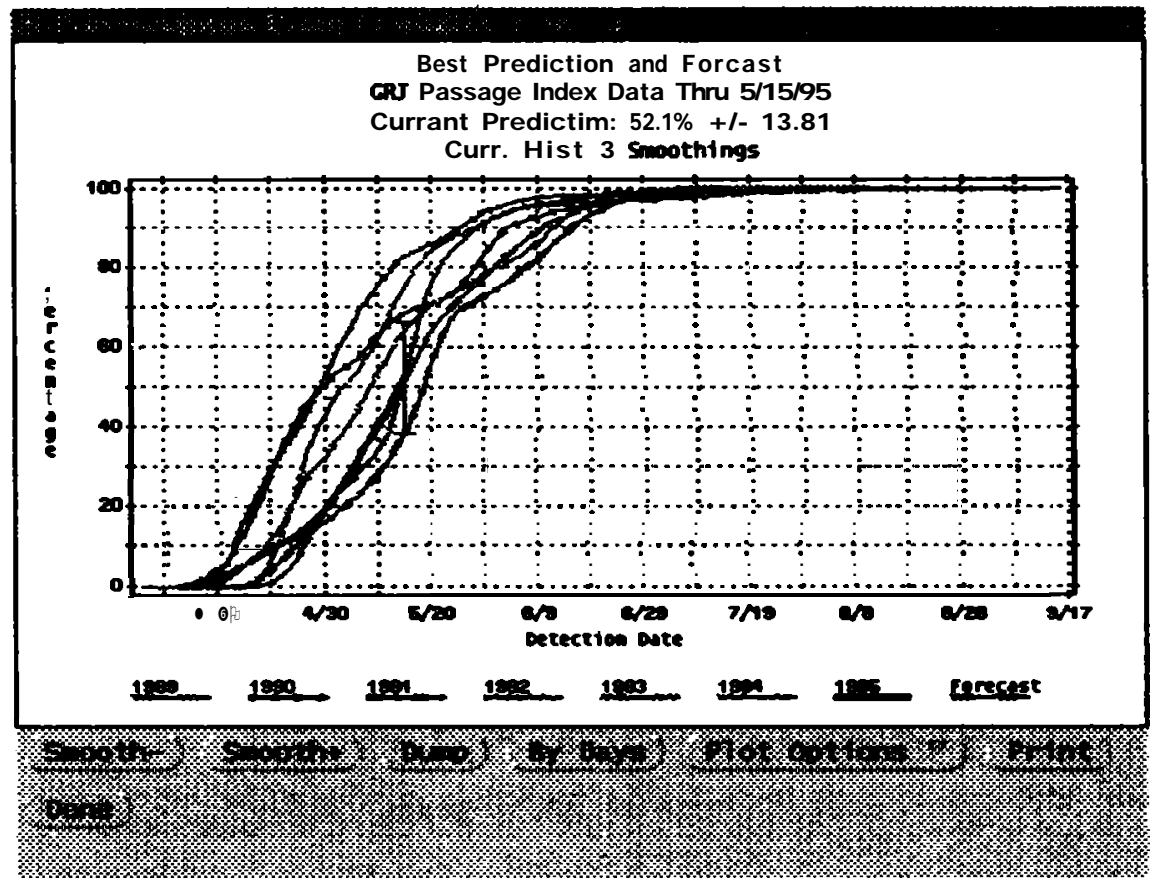

prediction and forecast window. These are similar to the displays far a single stream or rive-r on pages $6 \& 7$. 


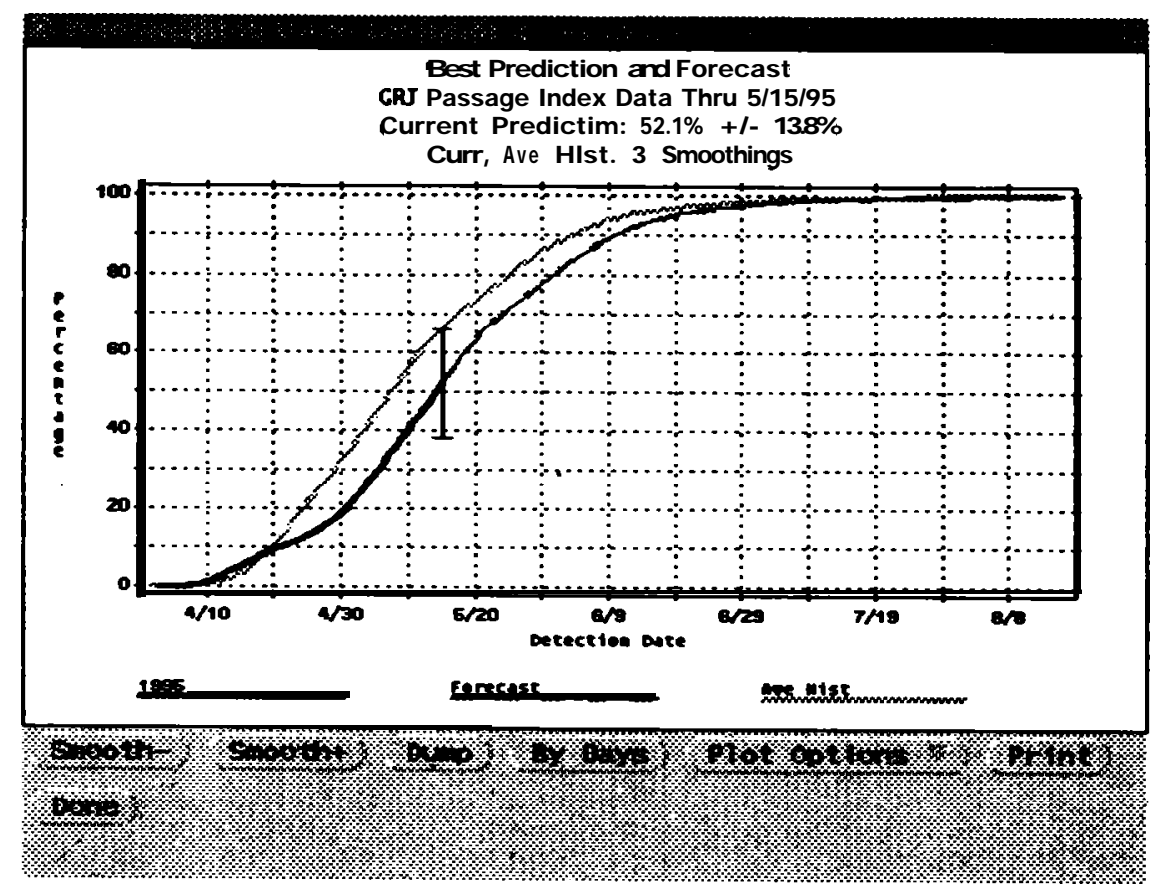

The prediction and forecast window for the composite run displays the current best prediction line versus the average historical line. The standard error is displayed by the bracket on the predicted day.

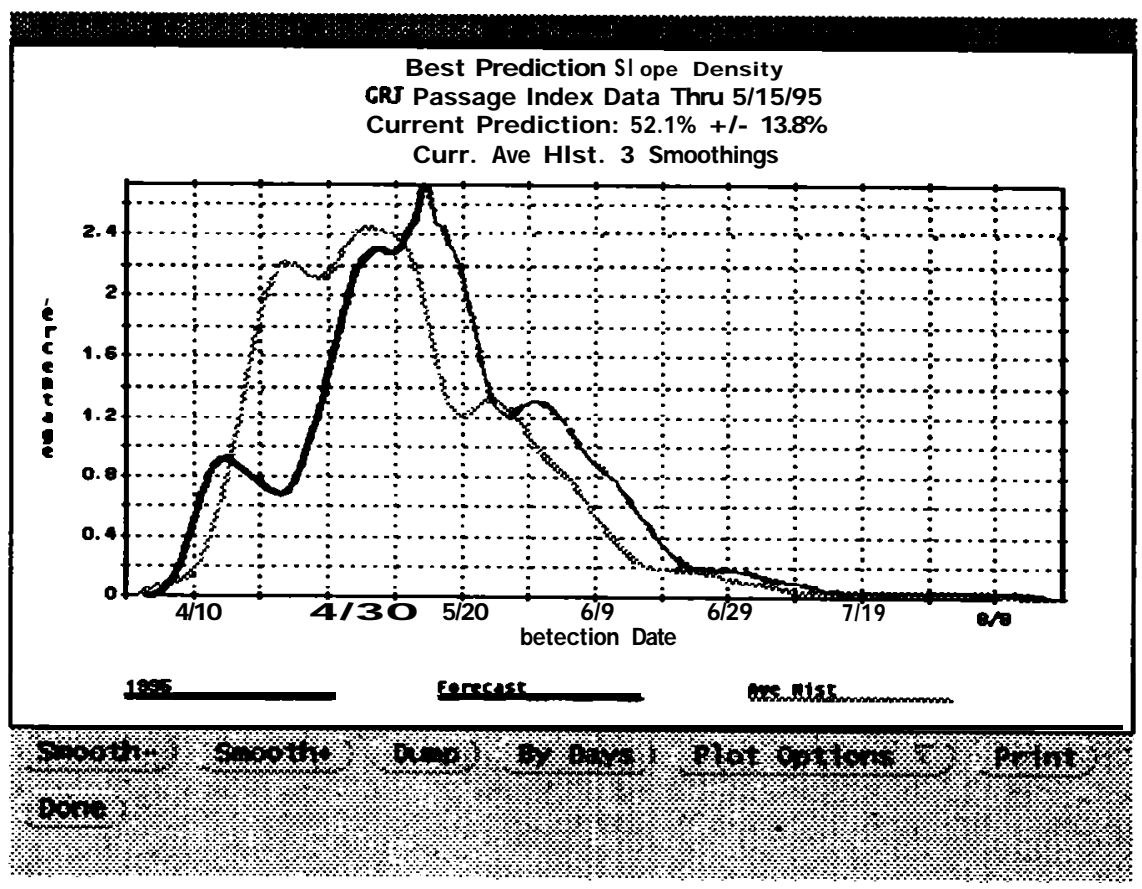

The prediction slope density window for the composite run displays the current slope density line versus tbe average historical line. 